\title{
Observed variations in convective precipitation fraction and stratiform area with sea surface temperature
}

\author{
Roberto Rondanelli ${ }^{1,2}$ and Richard S. Lindzen ${ }^{1}$ \\ Received 4 March 2008; revised 8 May 2008; accepted 6 June 2008; published 29 August 2008.
}

[1] This paper focuses on the relation between local sea surface temperature (SST) and convective precipitation fraction and stratiform rainfall area from radar observations of precipitation, using data from the Kwajalein atoll ground-based radar as well as the precipitation radar on board the TRMM satellite. We find that the fraction of convective precipitation increases with SST at a rate of about 6 to $12 \% / \mathrm{K}$ and the area of stratiform rainfall normalized by total precipitation decreases with SST at rates between -5 and $-28 \% / \mathrm{K}$. These relations are observed to hold for different regions over the tropical oceans and also for different periods of time. Correlations are robust to outliers and to undersampled precipitation regions. Kwajalein results are relatively insensitive to the parameters in the stratiform-convective classification algorithm. Quantitative differences between the results obtained using the two different radars could be explained by the smoothing in the reflectivity of convective regions due to the relatively large pixel size of the TRMM precipitation radar compared to the size of the convective clouds. Although a dependence on temperature such as the one documented is consistent with an increase in the efficiency of convective precipitation (and therefore consistent with one of the mechanisms invoked to explain the original Iris effect observations) this is but one step in studying the possibility of a climate feedback. Further work is required to clarify the particular mechanism involved.

Citation: Rondanelli, R., and R. S. Lindzen (2008), Observed variations in convective precipitation fraction and stratiform area with sea surface temperature, J. Geophys. Res., 113, D16119, doi:10.1029/2008JD010064.

\section{Introduction}

[2] The effect of microphysical processes in deep convective clouds remains a major source of uncertainty in understanding tropical cloud feedbacks on climate. Several studies have suggested on the basis of radiative convective equilibrium simulations [Sun and Lindzen, 1993; Renno et al., 1994; Emanuel and Pierrehumbert, 1996] and also on observational grounds [Lindzen et al., 2001; Lau and Wu, 2003; Del Genio and Kovari, 2002; Del Genio et al., 2005] that the temperature dependence of microphysical processes in deep convective clouds could result in climate feedbacks. In the context of the model presented by Renno et al. [1994] for instance, a low efficiency of precipitation resulted in warm and moist climates due to a strong water vapor feedback. Recently, Clement and Soden [2005] studied the sensitivity of the tropical mean radiative budget in a global climate model (GCM) to changes in the circulation and microphysics. They found a relatively large sensitivity to changes in the fraction of cloud that is converted to precipitation in deep convection compared to changes in

\footnotetext{
${ }^{1}$ Department of Earth, Atmospheric, and Planetary Sciences, Massachusetts Institute of Technology, Cambridge, Massachusetts, USA.

${ }^{2}$ On leave from Department of Geophysics, University of Chile, Santiago, Chile.

Copyright 2008 by the American Geophysical Union. 0148-0227/08/2008JD010064\$09.00
}

the strength of the Hadley circulation. Also using a GCM, Lau et al. [2005] found that an increased autoconversion rate in the parameterization of warm convective clouds leads to a stronger hydrological cycle, a reduction in upper level cloudiness, and an increase in the overall fraction of convective precipitation.

[3] Motivated by the previous work, we use radar observations to study the relation between sea surface temperature (SST) and the fraction of convective precipitation as well as the stratiform area normalized by precipitation in convective systems that develop over tropical oceans. Although our motivation for this study arises from the expectation that precipitation efficiency can control the water budget in convective systems thus ultimately acting as a climate feedback, we focus exclusively on the observational relation between convective fractions and stratiform area and SST, as opposed to the speculative attribution of a mechanism or the climate implications. We use data from the Kwajalein atoll ground-based radar (hereinafter referred to as KR) and the precipitation radar of the TRMM instrument (hereinafter referred to as PR), and we rely heavily on the algorithms that classify rainfall pixels into convective and stratiform. We realize that besides SST, other properties of the environment in which convection is growing will have an effect on the water budget of the convective systems, namely large-scale wind shear, relative humidity of the free troposphere, magnitude of the convective updrafts, etc. [see, e.g., Ferrier et al., 1996; 
Schumacher and Houze, 2006]. All these processes could provide plausible mechanisms for the relations between SST and detrainment properties documented in the literature. Not only can the local variation of SST be confounded by other processes that might bias the results but also some methodological provisions have to be made to account for the normalization of the results by a measure of convection. These provisions have been frequently overlooked when analyzing the climate implications of changes in the area of detrainment of convective systems.

[4] Notwithstanding these difficulties, there are theoretical reasons to suppose that a relation between SST and the efficiency of precipitation that is valid for the current and also for different climates may exist. On the basis of these theoretical arguments Lindzen et al. [2001] hypothesized that the observed reduction in the normalized area of high cirrus clouds with SST could be primarily associated with an increase in cloud liquid water with SST. As cloud liquid water increases, the formation of rainfall in convective clouds would become more efficient and therefore less condensate would be available for detrainment to form thin cirrus clouds in the upper troposphere. This is in essence the Iris hypothesis. In this paper, we deal, and only indirectly, with one aspect of the hypothesis, namely the possibility that an increase in precipitation efficiency with SST manifests itself as modifying the partition between the condensate that is rained out of the convective regions and the condensate that is transported to the stratiform anvil. In this regard, several observational studies, using a combination of satellite data, have recently provided evidence for an increase in the efficiency of precipitation with temperature over the tropical oceans [Del Genio and Kovari, 2002; Lau and Wu, 2003; Del Genio et al., 2005; Lin et al., 2006]. An increase in the precipitation efficiency with temperature is of course only one aspect of the problem. Related studies have dealt with several other aspects of the more general question of whether a negative feedback mediated by thin cirrus clouds does indeed exist. Using CERES and MODIS data, Choi and Ho [2006] estimated that about $60 \%$ of the tropical cirrus clouds have a positive cloud radiative forcing and therefore variations in their fraction with climate (currently covering $\sim 27 \%$ of the area of the tropics) could potentially induce strong feedbacks. Spencer et al. [2007] found a decrease in the ice tropical clouds during the warm phase of the tropical intraseasonal oscillation associated with a subsequent cooling of the troposphere. Su et al. [2008], however, studied the dependence of high cloud fraction on SST and found only a very small decrease in the cirrus area normalized by precipitation (similar to the absence of a signal documented by Rapp et al. [2005]) and a net positive cloud radiative forcing associated with these clouds. Methodological limitations related to the choice of the fraction of high cloud, to the choice of the normalization variable used to measure the amount of convection, and to the instrumental sampling in relation to the sampling of the evolution of a convective system can have a large effect on the quantitative results obtained as we will argue in the following sections. Some of these limitations may play a role in the absence of correlation between normalized high cloud and SST found by Rapp et al. [2005] and Su et al. [2008].

[5] In this paper we focus on the relation between convective precipitation fraction and stratiform area with
SST over the tropical oceans using two different instrumental data sets. We argue in section 2 that to the extent that the stratiform precipitation region is primarily controlled by the detrainment of water from the convective regions, the partition between convective and stratiform precipitation can be regarded as a useful, although admittedly rough, observable of the water budget in these systems. Section 3 presents results using the Kwajalein radar data set. In section 4 we attempt to extend the analysis to the rest of the tropical oceans and we discuss the origin of some of the differences found between the two different data sets, in particular differences in the pixel size, in the stratiformconvective separation algorithm and in sampling. Finally, in section 5 we offer some discussion and conclusions. Appendices A and B deal with the sensitivity of the Kwajalein results to the parameters of the stratiform and convective separation and with the statistical significance of the Kwajalein results.

\section{Data and Methods}

\subsection{Stratiform Convective Separation}

[6] There are physical as well as observational reasons for separating the precipitation produced by tropical mesoscale convective systems into stratiform and convective. Here we give a very brief account of these two precipitation types and the reader is referred to Houze [1993, 1997] for an extensive treatment of the terminology, physics, and observational aspects of the classification. The convective precipitation refers to the regions of the convective system in which vertical motion is strong $\left(w>1 \mathrm{~ms}^{-1}\right)$ and the formation of precipitation occurs mainly through the collection of cloud particles (coalescence or riming). On the other hand, stratiform precipitation regions are characterized by a slow ascent (less than about $1 \mathrm{~ms}^{-1}$ ) and the growth of the precipitation size particles occurs mainly by vapor diffusion on the surface of ice particles that were detrained from the convective region [Rutledge and Houze, 1987; Houze, 1997].

[7] From an observational perspective, the weak horizontal gradients of reflectivity in the stratiform regions can be distinguished from the peakedness of the reflectivity in the most vigorous convective regions, giving the basis for the algorithms to distinguish between convective and stratiform regions [Steiner et al., 1995]. The two types of precipitation are not independent of each other since the balance of water in each of the two regions of the system is coupled by the transport of condensate and water vapor from the convective region to the stratiform region [Houze, 1993]. However, besides detrainment of condensate from the convective regions, significant in situ condensation can also occur provided that there is a source of water vapor in the stratiform region. Observations of mesoscale convective systems in the tropics show the existence of a slantwise layer of ascent originating as a gravity wave response to the convective heating [Houze, 2004]. This mean ascent in the midtroposphere, with magnitudes of about 0.1 to $1.0 \mathrm{~ms}^{-1}$ [Cotton et al., 1995] provides a supplementary source of water vapor to the stratiform region. The relative importance of each of these two sources of condensate, that is the in situ condensate production and the detrainment from active convective regions in observed mesoscale systems, is large- 
ly unknown. However, Gamache and Houze [1983] estimated that the transport from the convective updrafts is the most important source of condensate in the stratiform region (about 1.5 to 3 times larger than in situ condensation in the stratiform region). Even if a significant fraction of the condensate is produced in situ, detrainment from the active convective towers seems to be a prerequisite for the existence of stratiform rainfall.

[8] As a consequence of this causal relation between the condensate produced in the convective elements and the stratiform precipitation, in the early stages of the life cycle of a mesoscale convective system, the precipitation will be mostly convective, whereas in the dissipating stages of the system, when detrainment has been efficient in producing a cloud anvil and active convective elements have decayed, the precipitation will be mostly stratiform. From these considerations we can expect that the partition between stratiform and convective precipitation can change widely if periods of time much smaller than the lifetime of the system are considered. Therefore, in order to assess a possible change in the partition of the precipitation between these two categories and SST, there is an essential need for an integral measure over the life cycle of the system. We define $\epsilon_{c}$ as,

$$
\epsilon_{c}=\frac{\int^{\tau} c(t) d t}{\int^{\tau}(c(t)+s(t)) d t}
$$

where $c$ and $s$ are the total convective and stratiform precipitation in the mesoscale convective system and $\tau$ is a timescale sufficiently long to encompass the entire evolution of the system. We also define a measure of the area of stratiform rainfall to the total precipitation of the system as a proxy for the spatial extent of the detrainment normalized by a measure of convection,

$$
\mathcal{A}_{s}=\frac{\int^{\tau} a_{s}(t) d t}{\int^{\tau}(c(t)+s(t)) d t},
$$

where $a_{s}(t)$ is the area of stratiform rainfall at each time over the life cycle of the system. In estimating the dependence of the distributions of $\epsilon_{c}$ and $\mathcal{A}_{s}$ on SST, we ideally would like to follow a large number of mesoscale convective systems over their complete life cycle. This would require a high temporal sampling over an area of a size at least comparable to the size of the largest mesoscale convective systems (a few hundred kilometers).

\subsection{Kwajalein Radar}

[9] The observational setting described in the previous section is most nearly found at the Kwajalein ground-based radar (KR). The KR is located on the Kwajalein atoll in the Republic of the Marshall Islands $\left(8.7^{\circ} \mathrm{N}, 167.7^{\circ} \mathrm{E}\right)$. The instrument covers an annular region of $17 \mathrm{~km}$ of internal radius and $150 \mathrm{~km}$ of external radius, which is enough to completely observe most of the mesoscale convective systems (about $1 \%$ of the systems can have cloud shields larger than the area covered by the radar [Houze, 1993]). The area covered by the radar is almost completely oceanic. The radar operates in the $\mathrm{S}$ band at a frequency of $2.8 \mathrm{GHz}$. In this work we make use of the University of Washington
Kwajalein data set, in particular the 2A53UW and 2A54UW products of the TRMM database, which correspond to the surface precipitation and the rain type classification, respectively. The temporal resolution of the data is about $10 \mathrm{~min}$. We have used the full data set available to date; it comprises 49 months between the years 1999 and 2003.

[10] The main uncertainties in the estimation of the average monthly area rainfall measured by the Kwajalein radar have been identified and quantified by Houze et al. [2004]. All of these uncertainties are also relevant to the stratiform convective separation. The most important uncertainty which accounts for fluctuations of $\pm 30 \%$ of the monthly mean value of rainfall is the calibration uncertainty. A calibration of the Kwajalein radar is performed by matching the areas of radar echo with reflectivity larger than $17 \mathrm{dBZ}$ at the $6-\mathrm{km}$ level with similar observations performed by the precipitation radar on board of the Tropical Rainfall Measuring Mission (TRMM) satellite. Other uncertainties include the extrapolation of surface reflectivity values made from the reflectivity at a higher level and the assumed $Z-R$ relationship based on observed distributions of rain droplet sizes.

[11] The classification of echoes into stratiform and convective is made from reflectivity measurements at the lowest level measured by the radar, following the procedure developed by Churchill and Houze [1984] and further refined by Steiner et al. [1995] and Yuter and Houze [1997].

\subsection{SST}

[12] We use the Pathfinder Version 5.0 SST data set, which is retrieved using the five channels of the Advanced Very High Resolution Radiometer (AVHRR). The daily maps of SST are averaged into 8-day and monthly periods. We use the 8-day period data to construct three time series of average SST, one over the region covered by the Kwajalein radar and the other two in regions of $5^{\circ} \times 5^{\circ}$ and $10^{\circ} \times 10^{\circ}$ centered at Kwajalein. Since SST is not estimated over pixels covered by clouds, significant gaps can occur over cloudy periods or regions. We use these two regions that are larger than the region that is sampled by the radar, in order to increase the accuracy of the average SST and also to account for the possibility that some detraining clouds could have originated from convection occurring outside the Kwajalein radar region.

\subsection{Radiosonde Data}

[13] Here we use 12-hourly operational soundings at Kwajalein (taken at $00 \mathrm{Z}$ and $12 \mathrm{Z}$ ) of temperature and dew point from all reported pressure levels for the period 1999 2003. The data were obtained from the NOAA Radiosonde Database access Web site (http://raob.fsl.noaa.gov/). The soundings were linearly interpolated from the reported pressure levels to $100 \mathrm{mb}$ intervals from $1000 \mathrm{mb}$ to $300 \mathrm{mb}$ and checked for obvious errors (missing data, unphysical values).

\section{Kwajalein Radar \\ 3.1. Results}

[14] The variables $\epsilon_{c}$ and $\mathcal{A}_{s}$ are calculated for varying periods of 8,16 , and 30 days, within the 5 years of available radar data. Periods in which less than $70 \%$ of valid data are 
Table 1. Percentage Change $\left(\% /{ }^{\circ} K\right)$ and Correlation Coefficient ( $r$ ) for the Linear Regression Between the Variables $\epsilon_{c}$ and $\mathcal{A}_{s}$ With Respect to $\mathrm{SST}^{\mathrm{a}}$

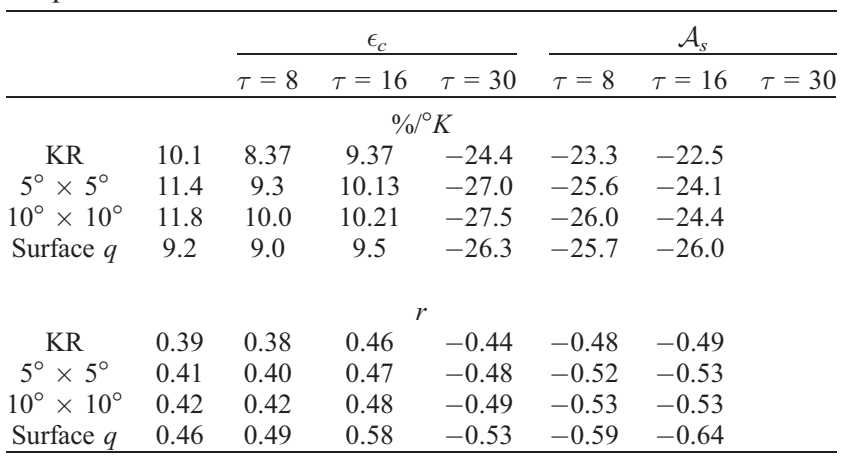

${ }^{a}$ Here $\tau$ is measured in days. The correlations are for the total of 5 years of ground-based radar data and for different periods of integration $\tau$ of 8 , 16 , and 30 days (the number of observations for the correlations is 162,76 , and 41 , respectively, for each of the periods). Only periods in which valid data are available more than $70 \%$ of the time are considered. KR (Kwajalein radar), $5^{\circ} \times 5^{\circ}$ and $10^{\circ} \times 10^{\circ}$ refer to the areas over which SST data is averaged, centered at Kwajalein. The row labeled "surface $q$ " shows the results for the linear regression using the surface $q$ averaged over the corresponding period instead of SST.

available are discarded from further analysis. Least squares linear regressions are performed and the slope of the regression (expressed as percentage increase per degree Kelvin) as well as the correlation coefficient $r$ are shown in Table 1. The scatter diagram for the period of 8 days using the average SST over the $10^{\circ} \times 10^{\circ}$ is shown in Figure 1 .

[15] Correlations between $\epsilon_{c}$ and SST are positive over the three different timescales considered and over the different regions over which the SST is averaged. The values for the slope of the linear regression are between $8 \% / \mathrm{K}$ and $12 \% / \mathrm{K}$. Correlation coefficients are low and explain a relatively small fraction of the variance of the data (15 to $25 \%$ ). However, the scatter is reduced as larger areas and longer periods of time are considered for the averages. As seen in Figure 1a the variance of the data seems to decrease with SST. The behavior of the variance might be expected given the low frequency of rainfall associated with colder SSTs and hence the temperature dependence of the sampling. We expect a larger scatter at relatively lower rainfall rates and a reduction of the difference in variance over the range of SST as we average over longer periods. This reduction of the variance is indeed observed when longer integration times are considered.

[16] The normalized stratiform area $\mathcal{A}_{s}$ has a negative correlation with SST and the value of the slope ranges between -22 and $-28 \% / \mathrm{K}$. The correlation coefficients are slightly larger than in the case of the correlations between $\epsilon_{c}$ and SST. We also notice the relatively large scatter particularly between $27^{\circ} \mathrm{C}$ and $28^{\circ} \mathrm{C}$. When the distribution of the residuals is calculated some outliers in the correlations are evident (the points that have $\epsilon_{c}<0.3$ in Figure 1a). Removing these outliers produces an insignificant change in the slopes (from $-27.5 \% / \mathrm{K}$ to $-27 \% / \mathrm{K}$ for $\mathcal{A}_{s}$ ).

[17] In order to evaluate the conjecture that the mechanism for the increase in the fraction of convective precipitation acts through the specific humidity of the air participating in convection, we have looked at how correlations differ when instead of using SST we use the average specific humidity at the surface as measured by the operational soundings at Kwajalein. The rows labeled "Surface $q$ " in Table 1 show the results for the linear regression of specific humidity $q$ and $\epsilon_{c}$ and $\mathcal{A}_{s}$. We see that the values of $r$ are slightly larger than for SST ( $r$ is 0.58 for $\tau=30$ days so they explain up to $35 \%\left(r^{2}\right)$ of the variance). This is a surprising result given the local nature of the radiosonde observations compared to the broader spatial extent of the remotely sensed SST. Figures $2 \mathrm{a}$ and $2 \mathrm{~b}$ show the regression of $\epsilon_{c}$ and $\mathcal{A}_{s}$ against the average $q$ at the surface for a period of integration of 8 days. In Figure 2c we show a regression a)

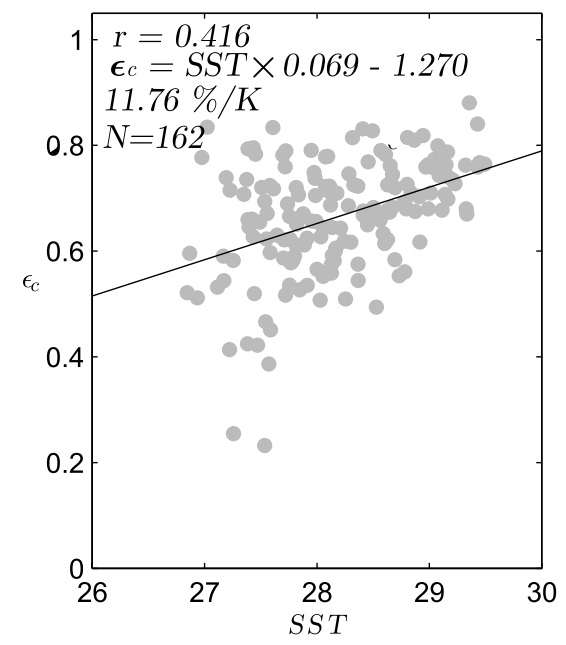

b)

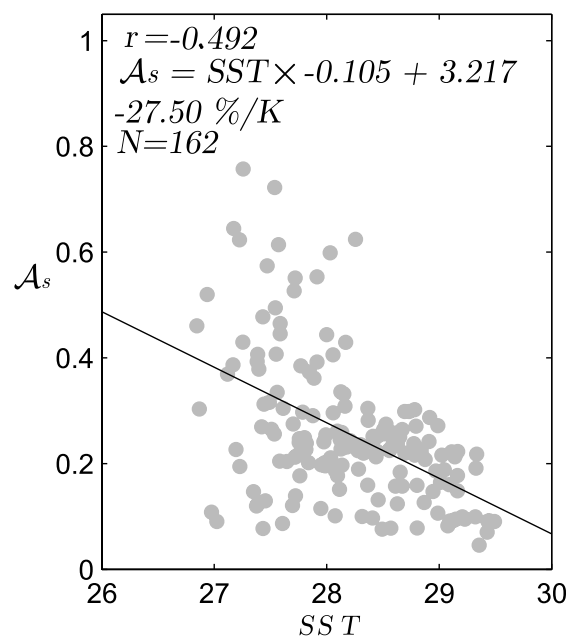

Figure 1. Linear regression between (a) convective fraction $\epsilon_{c}$ and (b) stratiform area per unit precipitation $\mathcal{A}_{s}$ with respect to the average sea surface temperature (SST) of a region of $10^{\circ} \times 10^{\circ}$ around Kwajalein. The period of integration is $\tau=8$ days. The units of $\mathcal{A}_{s}$ are $\mathrm{KR} /\left[\mathrm{mm} \mathrm{h}^{-1}\right]$, where $K R$ is the area covered by the Kwajalein radar. 

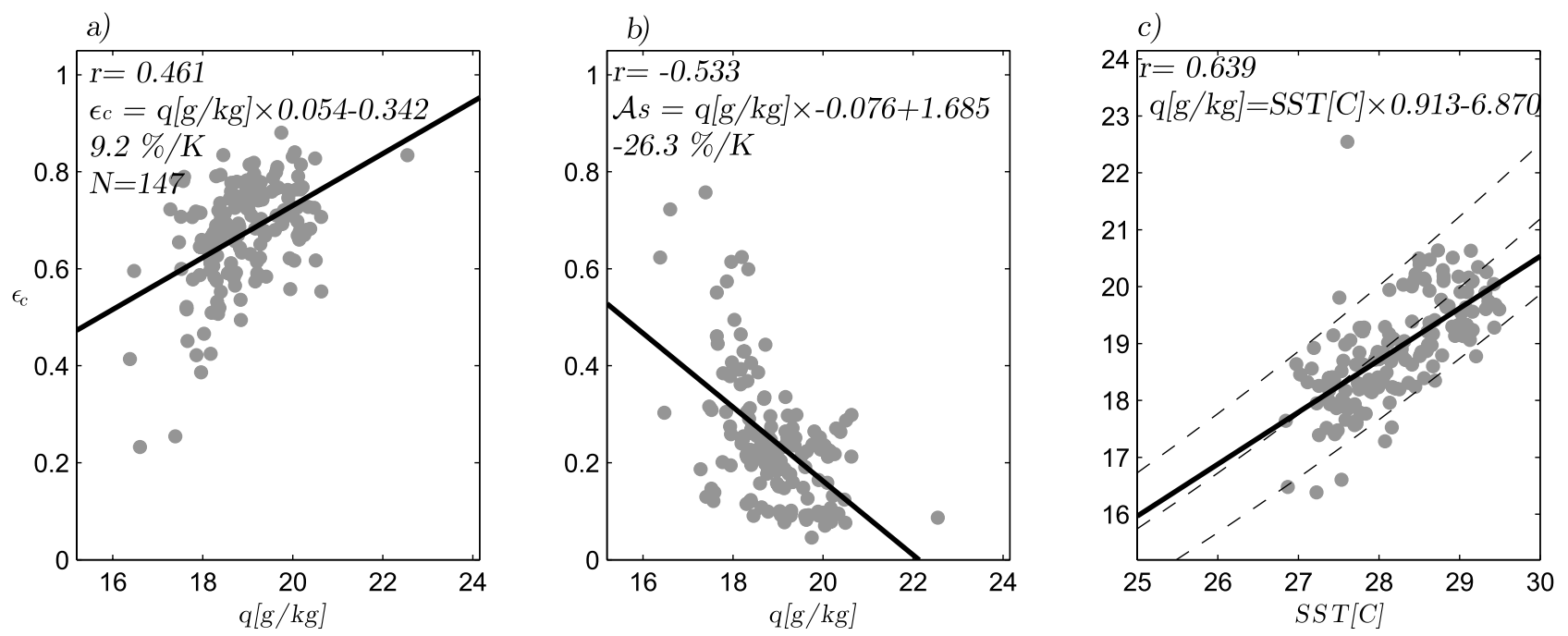

Figure 2. Linear regression of (a) $\epsilon_{c}$, (b) $\mathcal{A}_{s}$ and (c) SST averaged over the Kwajalein region on the average specific humidity at the surface as measured by the operational soundings at Kwajalein. The period of integration is $\tau=8$ days. (c) Dashed lines show the $0.75,0.80$, and 0.85 relative humidity curves as calculated from the Clausius-Clapeyron relation for the corresponding SST.

between the mean SST over the Kwajalein region and the specific humidity $q$ at the surface. At least two effects contribute to the scatter. The first is that the measurements are not completely comparable since the SST is averaged in space over the entire radar region, whereas $q$ is a local value. The second effect and probably the most important is that the relative humidity is not constant from one period to another and therefore different values of specific humidity are associated with a single SST. Besides the linear regression, we also plot in Figure 2c the curves corresponding to $0.75,0.80$, and 0.85 relative humidity according to the Clausius-Clapeyron relationship. We see that most of the data is contained within the 0.75 and 0.85 curves and that over the time scale of 8 days only about $40 \%$ of the variance in $q(r=0.64)$ is explained purely by changes in SST.
[18] In Figure 3 we show the result of the regression between $\epsilon_{c}$ and specific humidity in the vertical from the radiosonde measurements at Kwajalein. We see that correlations $(r \sim 0.4-0.5)$ and slopes are positive and relatively constant up to about $850 \mathrm{mb}$. The scatter increases above $800 \mathrm{mb}$ for all the time scales considered. We see that midtropospheric humidity is also positively correlated with $\epsilon_{c}$; however, slopes and scatter are consistently smaller above the $800 \mathrm{mb}$ level. This is the behavior than one would expect if the main control of $\epsilon_{c}$ would reside in the boundary layer. However, it is also possible that a single sounding site is less adequate to make inferences in the midtroposphere than in the boundary layer since the variability of specific humidity may be larger (due to episodic evaporative downdrafts and horizontal advection) than in
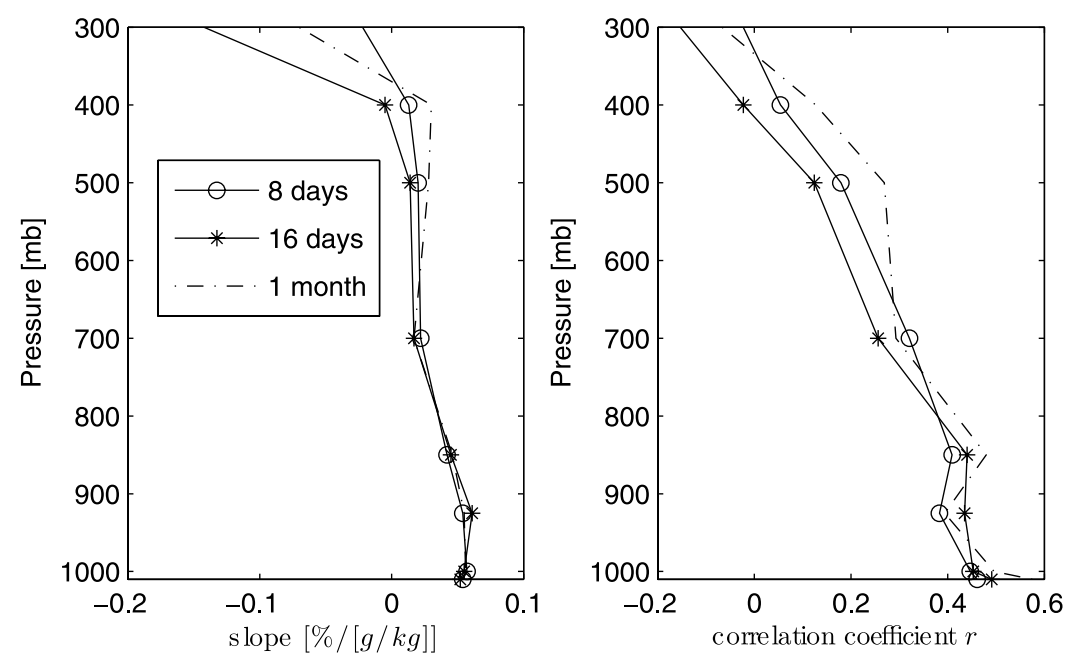

Figure 3. (a) Slope of the regression and (b) correlation coefficient between the convective fraction $\epsilon_{c}$ and the specific humidity as measured at different pressure levels by the radiosondes at Kwajalein. Correlations are shown for the three different integration periods. 
a)

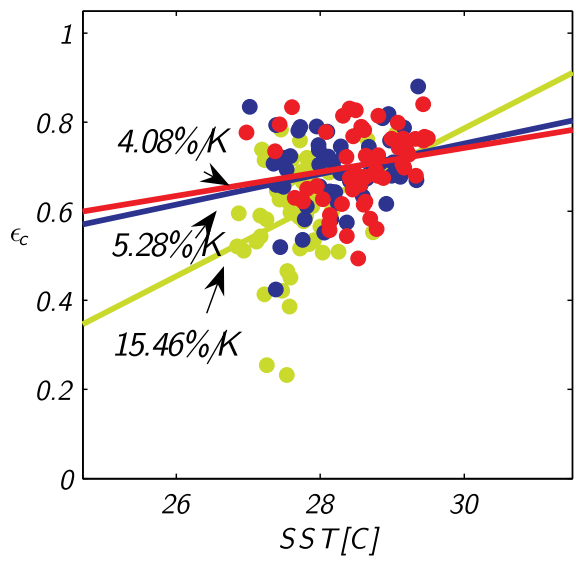

c)

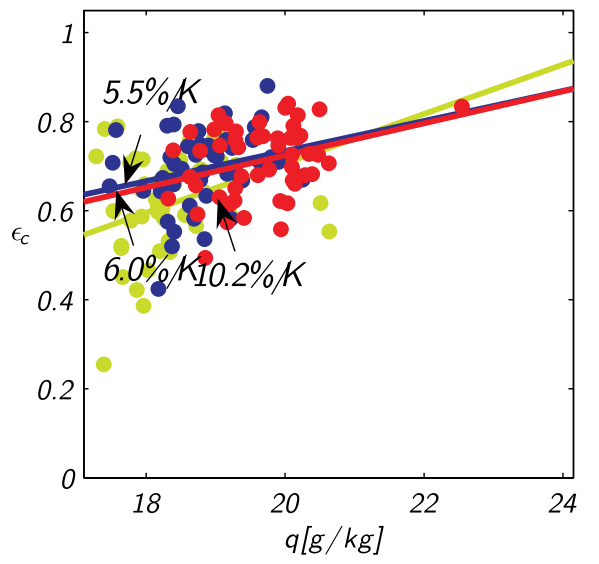

b)

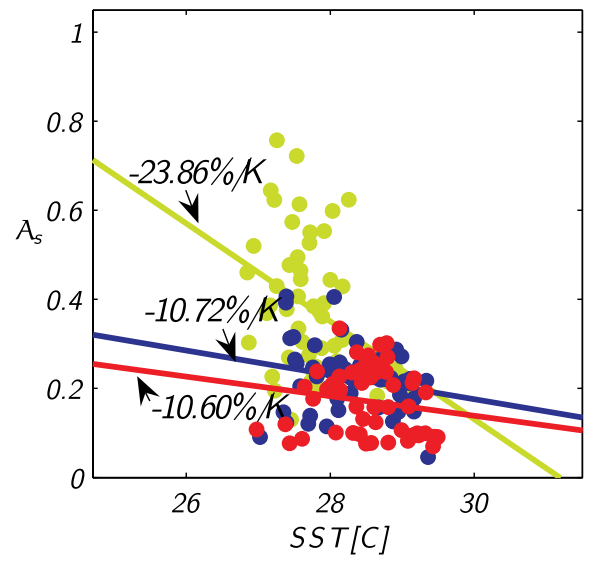

d)

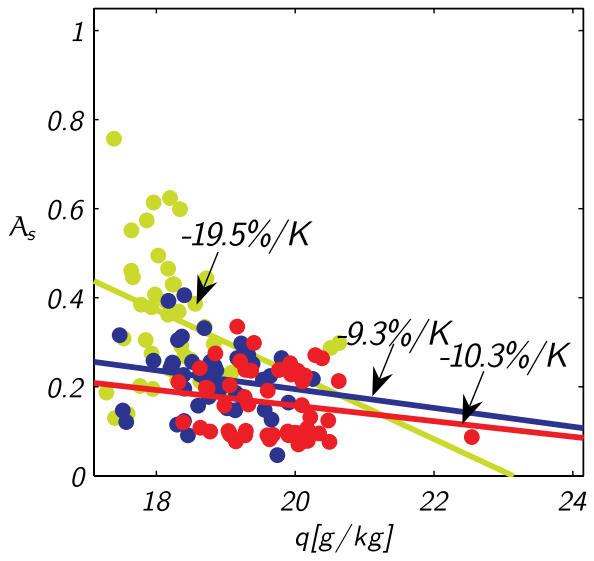

Figure 4. Linear regression between (a) $\epsilon_{c}$ and (b) $\mathcal{A}_{s}$ with respect to SST and (c) $\epsilon_{c}$ and (d) $\mathcal{A}_{s}$ with respect to $q$ at the surface. The colors represent the lower (yellow), medium (blue), and upper (red) tercile of the distribution of rainfall over the period.

the boundary layer where the specific humidity is relatively close to $80 \%$ of the saturation value at SST.

[19] We finally present the regressions using the results for the period of 8 days in which the sample has been divided into three similar subsamples according to the total rainfall observed during the period (Figure 4). The correlation coefficients in each of these regressions are smaller $(r \sim 0.2-0.3)$ than the ones in which the original sample is used, so inferences have to be made with even greater caution. To the extent that inferences can be made with these reduced samples, the results suggest that the regressions are somewhat dependent on the rainfall amount. The largest slopes are found for the lower rainfall category that contain some outliers from the original regression. This might indicate that some of the original numbers for the slopes of the regression might be overestimated. It might also indicate that the linear regression is not adequate in this case. For the medium and the higher rainfall categories the slopes appear to be similar, between $4 \% / K$ and $6 \% / K$ for the increase of $\epsilon_{c}$ and around $-10 \% / K$ for $\mathcal{A}_{s}$ (significantly smaller than the number estimated using the totality of the data). The fact that at least the two larger rainfall categories show similar regressions might be interpreted as evidence that midtropospheric humidity variations, that are expected to be related to the total rainfall over the region, are not a dominant factor in the correlations.

\section{TRMM Precipitation Radar}

[20] Although the KR provides a high temporal and spatial resolution data set of stratiform and convective rainfall, the data set only represents a very small area of the tropical ocean. The obvious choice to extend the analysis to the rest of the tropical oceans is to use data from the precipitation radar on the TRMM satellite (PR). The PR instrument provides estimations for the rainfall and classification for each rainfall pixel [Awaka et al., 1997; Iguchi et al., 2000; TRMM Precipitation Radar Team, 2005] (products 2A23 and 2A25A, version 6). The TRMM satellite orbits the Earth at a height of about $350 \mathrm{~km}$ and with an inclination of about $35^{\circ}$. The precipitation radar (PR) on board TRMM measures at a frequency of $13.8 \mathrm{GHz}$. Significant attenuation occurs at this frequency primarily by rainfall and has to be corrected before producing the precipitation product [Iguchi et al., 2000]. The data is gathered over a swath width of $215 \mathrm{~km}$ with a horizontal resolution of $4.3 \mathrm{~km}$ at nadir (for data before August 2001) and a vertical resolution of $250 \mathrm{~m}$. The instrument is sensitive 


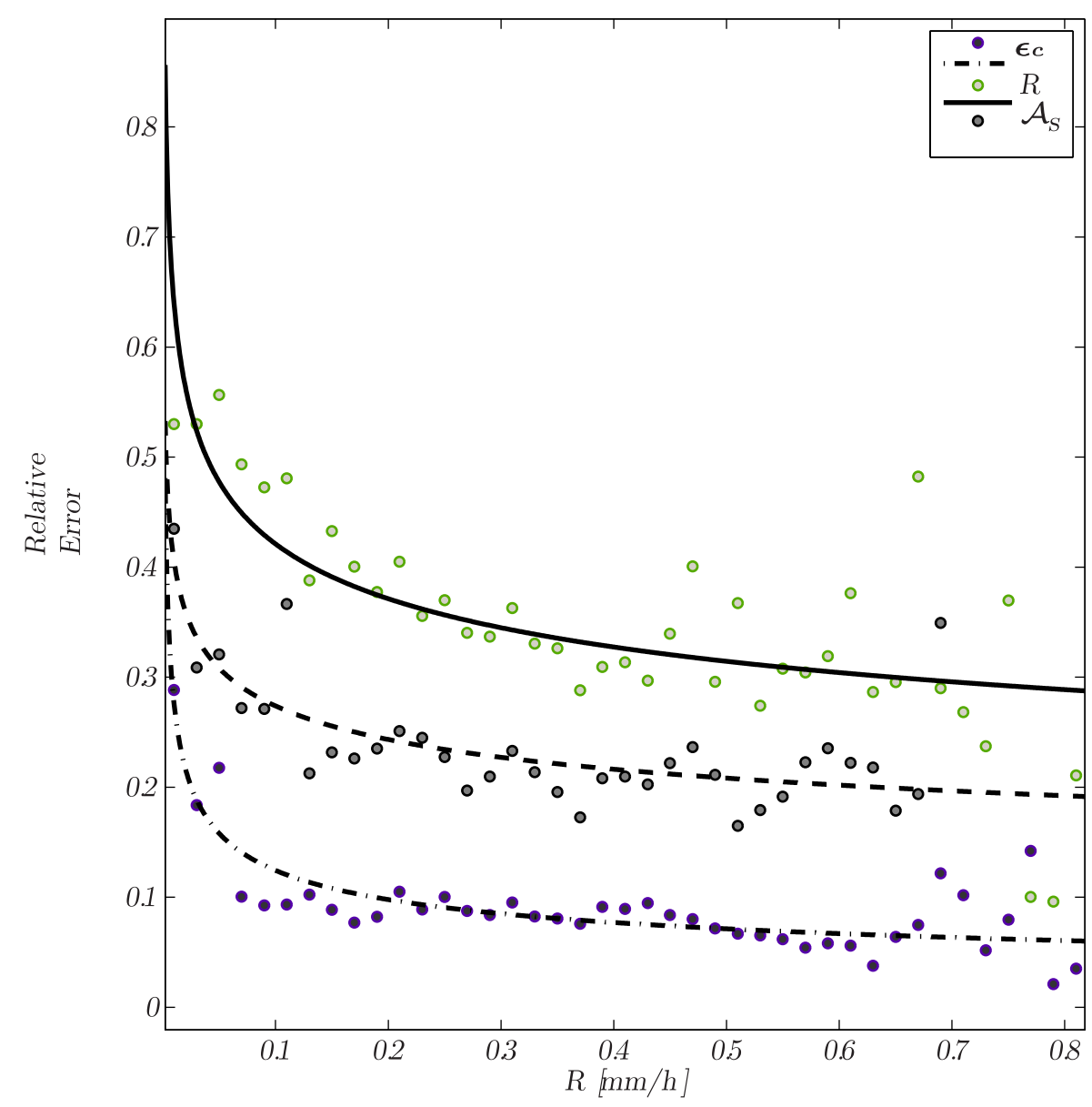

Figure 5. Relative sampling error estimated for TRMM revisit times using resampling of the Kwajalein radar data. The curves are the least squares fitting of a power law for the three variables, $\epsilon_{c}$ (dash-dotted line), $\mathcal{A}_{s}$ (dotted line), and total rainfall $R$ (solid line). The fitting is done for the average value of the relative sampling error binned according to rainfall in $\mathrm{mm} \mathrm{h}^{-1}$.

to echoes with reflectivity higher than about $18 \mathrm{dBZ}$ (for more details, see, e.g., Kummerow et al. [1998]).

[21] The immediate extension of the Kwajalein analysis using the PR data is not free of limitations. Perhaps the most important limitation is the inability to resolve mesoscale convective systems due to the low temporal resolution of the PR orbits. A region of the size of the area covered by the $\mathrm{KR}$ will be, on average, completely covered by the footprint of the PR once in about 3 days compared to the 10 min time resolution provided by the KR. A strategy to use the PR data has to balance the need to use a sufficiently long period of time to minimize the sampling error and a sufficiently short period of time so that the SST measured over that period is not significantly different from the SST relevant to the convective timescale.

\subsection{Estimating TRMM Sampling Error Using the Kwajalein Data Set}

[22] In this section we will estimate the sampling error made by the PR in monthly accumulations of orbital data by using resampling over the more frequent KR data. We can form synthetic months by taking a piece of the original 5 year series long enough so that is larger than the decorrelation time for the the particular variable observed. In the case of average rainfall, and for this particular grid size, the decorrelation time is about 5 days, so we arbitrarily choose the length to be 10 days. We create 1000 synthetic months out of the Kwajalein data and at the same time we preserve the statistical characteristics of the time series for the shorter scales. A similar methodology was suggested by Bell and Kundu [2000].

[23] Figure 5 shows the dependence of the relative root mean squared error with rainfall for the three variables, $\epsilon_{c}$, $\mathcal{A}_{s}$, and $R$. The curves are least squares fitting of power laws for each of the variables. We see that the relative error for rainfall is between $20 \%$ and $50 \%$ for the revisit time of the TRMM instrument, whereas the sampling error for $\mathcal{A}_{s}$ is between $20 \%$ and $30 \%$ and the error for $\epsilon_{c}$ is only about $10 \%$. This behavior seems consistent with the idea of a relatively longer decorrelation timescale for $\epsilon_{c}$ and $\mathcal{A}_{s}$ than for $R$ itself as the relative sampling error is inversely proportional to the decorrelation time. The dependence of the sampling error on rainfall is similar to other observational estimates and also to the theoretical model presented by Bell and Kundu [2000] that predicts a $R^{-\frac{1}{2}}$ dependence of the relative error of rainfall and a sampling error of magnitude inversely proportional to the decorrelation timescale. The power law dependence for the relative sampling error of rainfall in our case seems to be closer to $R^{-\frac{p}{5}}$. 

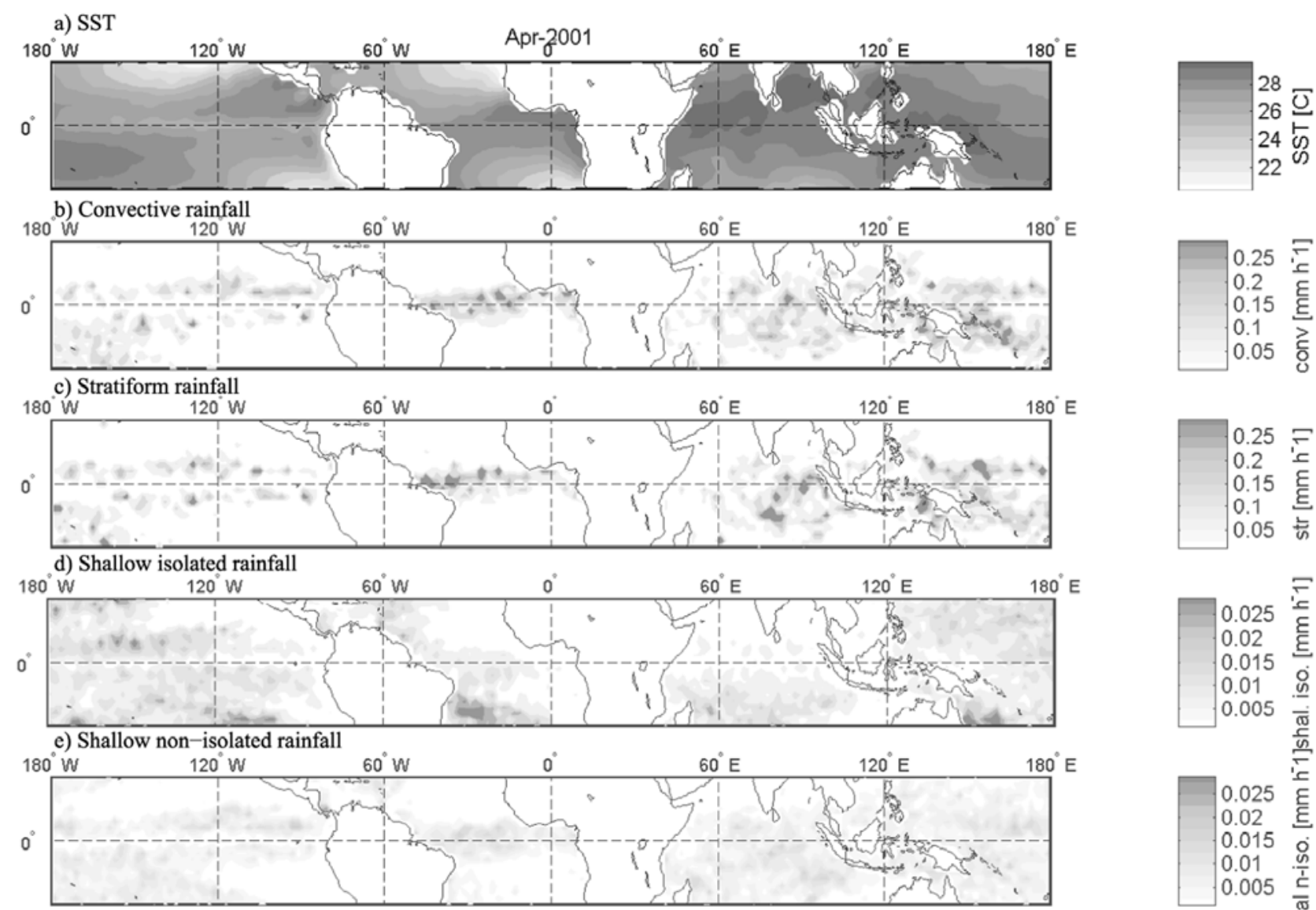

Figure 6. Rainfall intensity for different categories according to TRMM-PR for April 2001. (a) Sea surface temperature. (b) Convective rainfall (200-240). (c) Stratiform rainfall (100-170). (d) Shallow isolated rainfall $(251,261,271,281,291)$. (e) Shallow nonisolated rainfall $(252,262,272,282)$.

However a $R^{-\frac{1}{2}}$ curve that fits the data is within the standard deviation of the average of the errors depicted in Figure 5.

[24] The existence of the sampling error does not a priori precludes the possibility of observing a signal in the TRMM data. The sampling error, if uniform over the range of temperatures, will only decrease the confidence of the estimation of the parameters of the regression to the extent of the magnitude of the error. Since the scatter of the regression not only depends on the error but also on the proportion of the variance of the error to the variance of the dependent variable, the detection of the signal is made difficult both by the sampling and also by the relatively small range of temperatures over which deep convection occurs.

\subsection{PR Convective-Stratiform Classification}

[25] The classification of echoes among two broad categories is done using both the vertical and horizontal variability of the reflectivity in TRMM [Awaka et al., 1997; TRMM Precipitation Radar Team, 2005]. Given the relatively high vertical resolution of TRMM of $250 \mathrm{~m}$, a bright band (that is, a region of a few hundred meters in the vertical of enhanced reflectivity due to melting of ice hydrometeors [Doviak and Zrnic, 1993]) can be determined providing a complementary method to the horizontal texture classification algorithms [e.g., Steiner et al., 1995]. Using the height of the storm top (the maximum height at which significant echo is observed) a shallow and nonshallow classification is performed. Also all rainy pixels are classified as isolated or nonisolated, depending on whether they are surrounded by other rainy pixels.

[26] We show in Figure 6 the geographical distribution of rainfall separated in four broad categories constructed by merging some of the original categories in the $2 \mathrm{~A} 23$ product as indicated in Figure 7 for the month of April 2001. We see that convective and stratiform rainfall pixels are constrained to the ITCZ regions in the Atlantic and Eastern Pacific (where there is a hint of a double ITCZ) and they are more widespread in the Indian Ocean and in the Western Pacific. Figure 6d shows the distribution of shallow isolated pixels; these are usually called cumulus congestus and they are precipitating clouds capped by an inversion layer near the freezing level as described by Johnson et al. [1999]. Although these clouds are convective in nature as argued by Schumacher and Houze [2003], they are not necessarily associated with detraining mesoscale convective systems. Shallow isolated rainfall is more prevalent in subtropical (the Eastern coasts of South America and Australia close to $20^{\circ} \mathrm{S}$ in this particular month), in which no corresponding stratiform or deep convective precipitation is observed. 


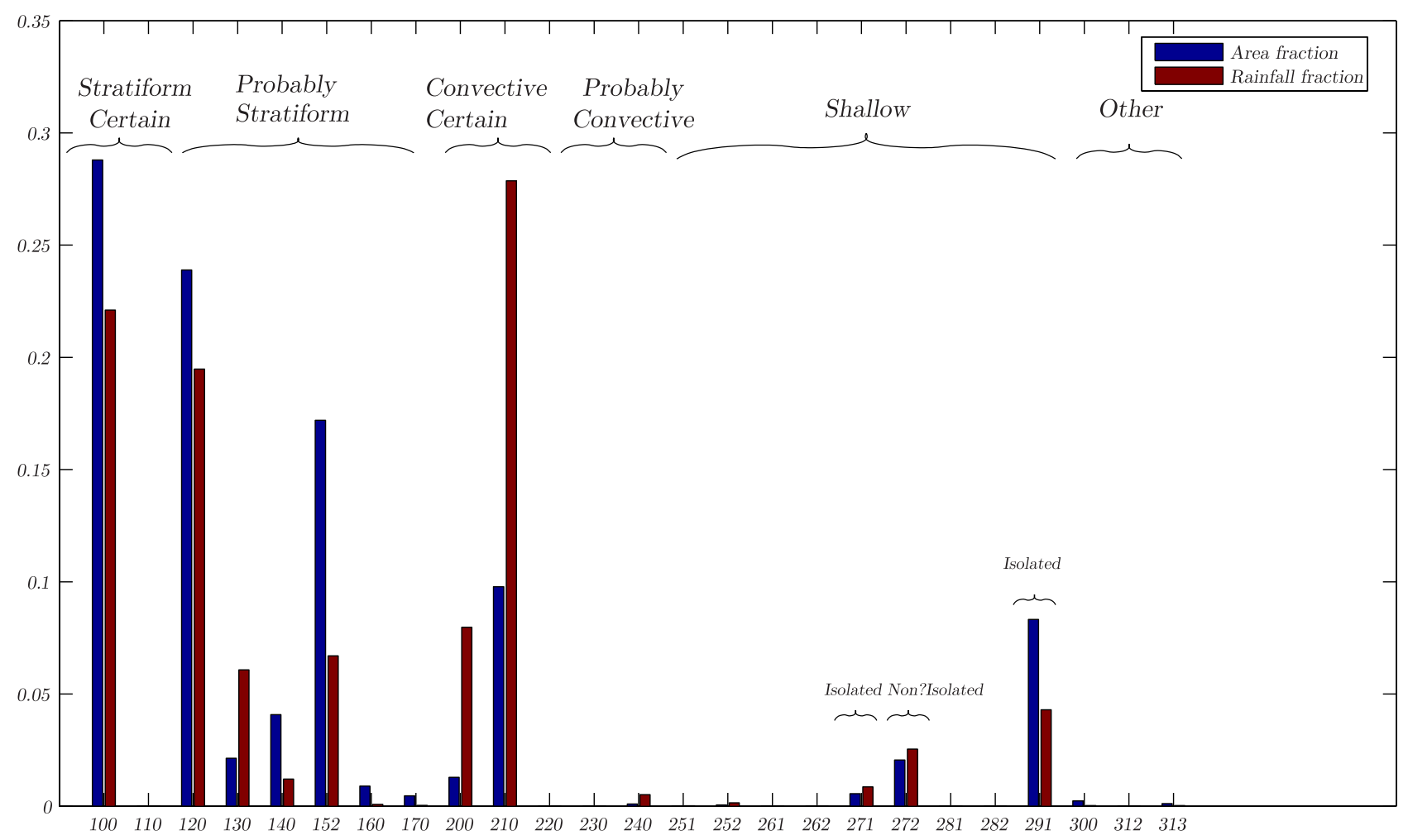

Figure 7. Distribution of rainfall and area according to the TRMM classification for the orbits that are coincident to Kwajalein over 5 years of data. Abscissa is numbered according to the different subcategories, and we have also labeled some of the categories.

Although shallow isolated pixels are also also observed over regions of deep convection we have decided to leave these pixels out of the convective category in our analysis (including these pixels makes only a minor quantitative difference in the results). We realize that this might not be necessarily consistent with the Kwajalein analysis; however, including these pixels in the convective category in regions in which deep convection is frequently observed does not have a large impact, as can be deduced from Figure 7 which indicates that shallow isolated rainfall makes up about 5\% of the total rainfall for these particular orbits over Kwajalein. (A caveat to this argument is that the prevalence of shallow isolated rainfall can be seriously underestimated by TRMM, as we will discuss in section 4.4.) On the other hand, there are also shallow nonisolated pixels and their distribution is shown in Figure 6e. By definition these pixels are located closer to the deep convective systems in the tropics, and, not surprisingly, their distribution resembles the distribution of deep convective and stratiform rainfall; therefore we have included these pixels under the convective category.

[27] Figure 7 shows the histogram of the different subcategories of precipitation derived from the classification algorithm of PR. Figure 7 was made using a small set of TRMM orbits coincident with the Kwajalein region.The labels on the top of Figure 7 are based on the TRMM categories provided, in which probably convective and probably stratiform are used to denote pixels in which only one of either the vertical or the horizontal method classified the pixel in the corresponding category. Hereafter and for the purpose of the analysis, stratiform will include those pixels classified as "stratiform certain," "probably stratiform," as well as the "other" category. Convective will include pixels classified as "convective certain," "probably convective," and "shallow nonisolated" as argued above.

\subsection{Results}

[28] Correlations between $\epsilon_{c}, \mathcal{A}_{s}$, and SST are shown in Figure 8 . The correlations are calculated for monthly data over strictly oceanic grids of $2^{\circ} \times 2^{\circ}$ size for the year 2001 between $20^{\circ} \mathrm{S}-20^{\circ} \mathrm{N}$. Each of the small dots represents a single grid in which the monthly values of the variables have been estimated from the available orbits. We notice that the classification algorithm detects "deep convection" even in regions in which the monthly average SST appears too cold to sustain tropical convective systems. It is possible that these convective systems are simply cumulus congestus that grow above the freezing level and are classified alternatively as either convective or stratiform. To avoid biases due to this or other possible artifacts, we also bin all data according to SST regardless to their spatial location (large dots in Figure 8). We will refer to these two related data sets as gridded and binned. Table 2 summarizes the relative change with temperature deduced from the regressions for different size of the gridding of the orbital data, as well as for two different subdomains within the $20^{\circ} \mathrm{N} 20^{\circ} \mathrm{S}$ tropical belt. The regressions for $\epsilon_{c}$ are linear and for $\mathcal{A}_{s}$ are exponential. In the case of the binned data, we have used a robust regression weighted according to the number of samples in each bin. In this way the correlations are representative of the regions in which deep convective pixels are more prevalent. 
$20^{\circ} \mathrm{S}-20^{\circ} \mathrm{N}\left[2^{\circ} \times 2^{\circ}\right]$
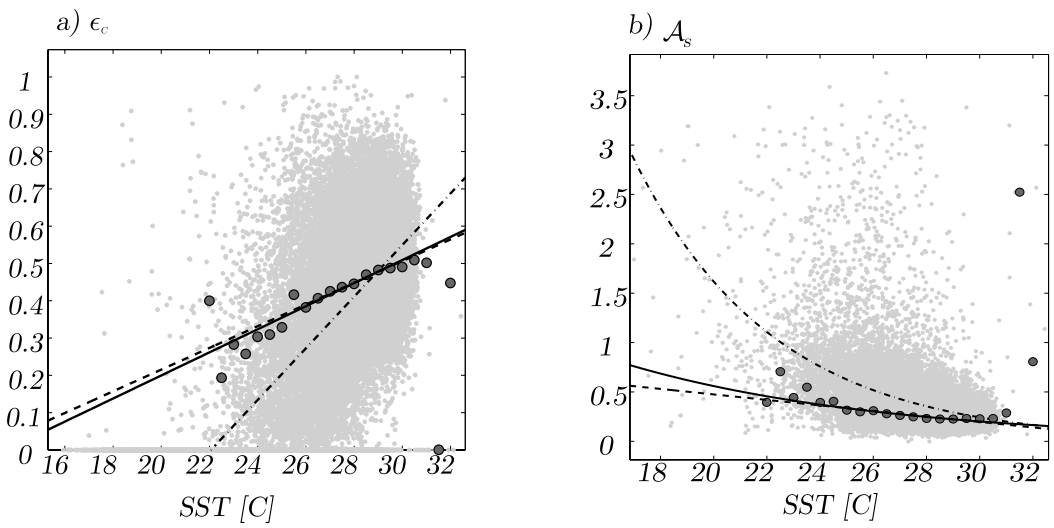

Figure 8. Regression of the variables (a) $\epsilon_{c}$ and (b) $\mathcal{A}_{s}$ with respect to SST obtained from the TRMM data set for the year 2001, when the pixel data were aggregated monthly in time and in grids of size $2^{\circ} \times$ $2^{\circ}$ in space. Light gray dots are monthly $2^{\circ} \times 2^{\circ}$ observations, whereas dark gray circles are obtained after adding all data for a given SST range (binned data). The curves in Figures $8 \mathrm{a}$ and $8 \mathrm{~b}$ are different versions of the least squares fitting (LS) of the data, in linear LS of all the data (dash-dotted line), the linear LS of all binned data (dashed line), and robust linear LS of the binned data (solid line) in Figure 8a. In Figure $8 \mathrm{~b}$ the curves are the exponential LS of all data (dash-dotted line), the exponential LS of the binned data (dashed line), and the robust exponential LS of the binned data (solid line).

[29] The gridded data shows a relatively large scatter $\left(r^{2}\right.$ is about 0.25 for both variables). When the regression is taken on the binned data, the scatter and the magnitude of the slope of the regression are reduced. As shown in section 4.2, the sampling error has a rainfall dependence; on the other hand, rainfall has a positive dependence on temperature over the tropical oceans. Therefore, it is expected only on the basis of the nature of the sampling error that the variance of the gridded data will also show a SST dependence. Consistent with the sampling error being larger for relatively cold SSTs, the difference between the gridded and binned regression is largest in the colder regions specially for $\mathcal{A}_{s}$ as shown in Figure 8.

[30] Table 2 also shows the results for two subdomains; the Western Pacific (WP) is defined as the region between $140^{\circ} \mathrm{E}$ and $150^{\circ} \mathrm{W}$, whereas the EP is the region between $150^{\circ} \mathrm{W}$ and $80^{\circ} \mathrm{W}$. Correlations in the EP region have a smaller scatter (for instance, for $\epsilon_{c}, r^{2}=0.16$ in the WP compared to $r^{2}=0.28$ in the EP) and also a larger slope for the correlation. Correlations are positive for each region separately suggesting that the correlation is universal. Figure 9 shows the regressions for the EP and WP regions. The regression in both figures are the robust regressions for the binned data sets in each of the regions. In general it seems that for the same SST the EP shows a higher value of $\epsilon_{c}$ and a smaller value of $\mathcal{A}_{s}$. This seems in apparent contradiction with observations that indicate a higher proportion of stratiform rainfall in the EP than in the WP [e.g., Berg et al., 2002; Schumacher and Houze, 2003]. However, given the larger proportion of relatively colder SSTs over the EP, at least for the year 2001 the overall fraction of convective precipitation is smaller in the EP than in the WP region.

[31] We notice that $\epsilon_{c}$ is smaller for Kwajalein than what is observed with the PR. However in terms of the relative change with temperature, PR results seem to agree quanti- tatively with the range between 8 to $12 \% / \mathrm{K}$ increase for $\epsilon_{c}$ obtained from the Kwajalein observations. In the case of $\mathcal{A}_{s}$, PR correlations are smaller than those obtained for KR, specially over the Western Pacific where the relative change in $\mathcal{A}_{s}$ can be about $-5.5 \% / K$, compared to $-22 \% / K$ for Kwajalein. We also notice that the rate of change of $\mathcal{A}_{s}$ with temperature seems closer to zero for temperatures higher than about 28.5 C (Figure 8b), so even an exponential decrease does not seem to be an appropriate fit for this part of the curve. This flattening toward higher temperatures might be a consequence of the instrument resolution as we will discuss in section 4.4. However, we can anticipate that to the extent that PR errors can be reduced by binning the data with SST, and considering some of the differences in the instruments as well as in the classification methods, PR and KR seem to agree in the magnitude and sign of the variation with SST of $\epsilon_{c}$ and $\mathcal{A}_{s}$.

\subsection{Kwajalein and PR Radar Comparison}

[32] In order to discuss the differences between the Kwajalein and TRMM results, it is useful to compare the

Table 2. Relative Increase in $\epsilon_{c}$ and $\mathcal{A}_{s t r}$ With SST Estimated From the Regression of the Data From the Precipitation Radar on Board the TRMM Satellite

\begin{tabular}{lccccc}
\hline & & \multicolumn{3}{c}{$2^{\circ} \times 2^{\circ}$} & \\
\cline { 3 - 5 } \cline { 3 - 4 } & Data Type & All & WP & EP & All \\
\hline$\epsilon_{c}(\% / \mathrm{K})$ & gridded & 13.9 & 13.1 & 17.8 & 12.4 \\
& binned & 6.47 & 6.7 & 10.7 & 6.98 \\
$\mathcal{A}_{s}(\% / K)$ & gridded & -21.8 & -15.9 & -17.7 & -18.9 \\
& binned & -15.6 & -5.5 & -12.6 & -10.2 \\
\hline
\end{tabular}

${ }^{\text {a}}$ The results are given in $\left(\% /{ }^{\circ} \mathrm{C}\right)$ at $27^{\circ} \mathrm{C}$. "All" refers to the calculations including all oceanic regions. WP and EP stand for western Pacific and eastern Pacific, respectively. All calculations are between $20^{\circ} \mathrm{S}$ and $20^{\circ} \mathrm{N}$, except for the column indicated as $10^{\circ} \mathrm{S}$ and $10^{\circ} \mathrm{N}$. 
West Pacific - East Pacific $\left[2^{\circ} \times 2^{\circ}\right]$
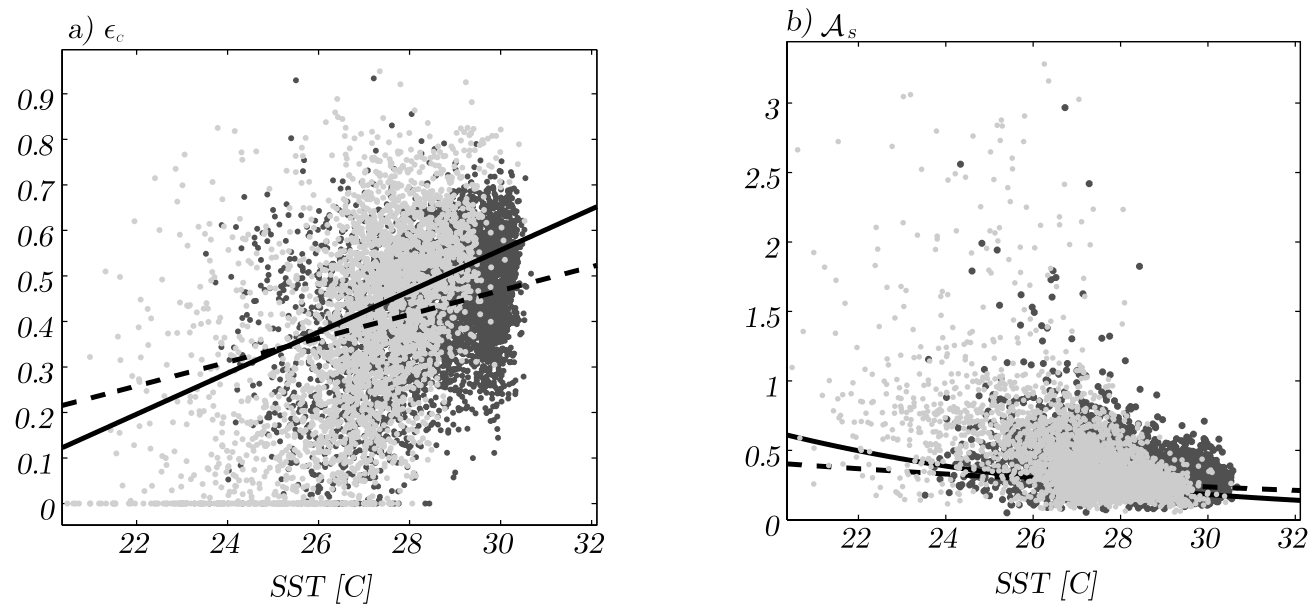

Figure 9. Same as Figure 8 but the data have been divided into west Pacific grids (dark grey) and east Pacific grids (light grey). The regression curves are the robust LS estimates of the binned data for each region, EP (solid curve) and WP (dashed curve). The regressions are robust, and linear for $\epsilon_{c}$ and exponential for $\mathcal{A}_{s}$.

classification and rainfall of pixels when both instruments are measuring the same region at the same time. We used all simultaneous TRMM orbits within 10 min of a radar scan made by the ground-based radar at Kwajalein and close enough in space to have a significant coverage $(\sim 60 \%$ in average) of the Kwajalein area by the swath of the PR. We identified 176 orbits fulfilling these conditions over the period of 5 years of the Kwajalein radar record. Previous work by Schumacher and Houze [2000] focused on the differences in reflectivity between these two instruments. Since the KR is calibrated based on matching the reflectiv- ity areas, we have done our comparison using rainfall rather than reflectivity to emphasize differences without regard to their origin (different Z-R relations, instrument sensitivity). Figure 10 shows the distribution of rainfall according to the two broad categories of stratiform and convective rainfall for the coincident orbits. One of the most noticeable differences is the higher sensitivity of the KR to lower rainfall rates which appears in the histogram as a $\mathrm{KR}$ stratiform distribution extending towards values smaller than $0.1 \mathrm{~mm} \mathrm{~h}^{-1}$ (notice logarithmic scale in Figure 10). For the same region in the histogram the PR distribution

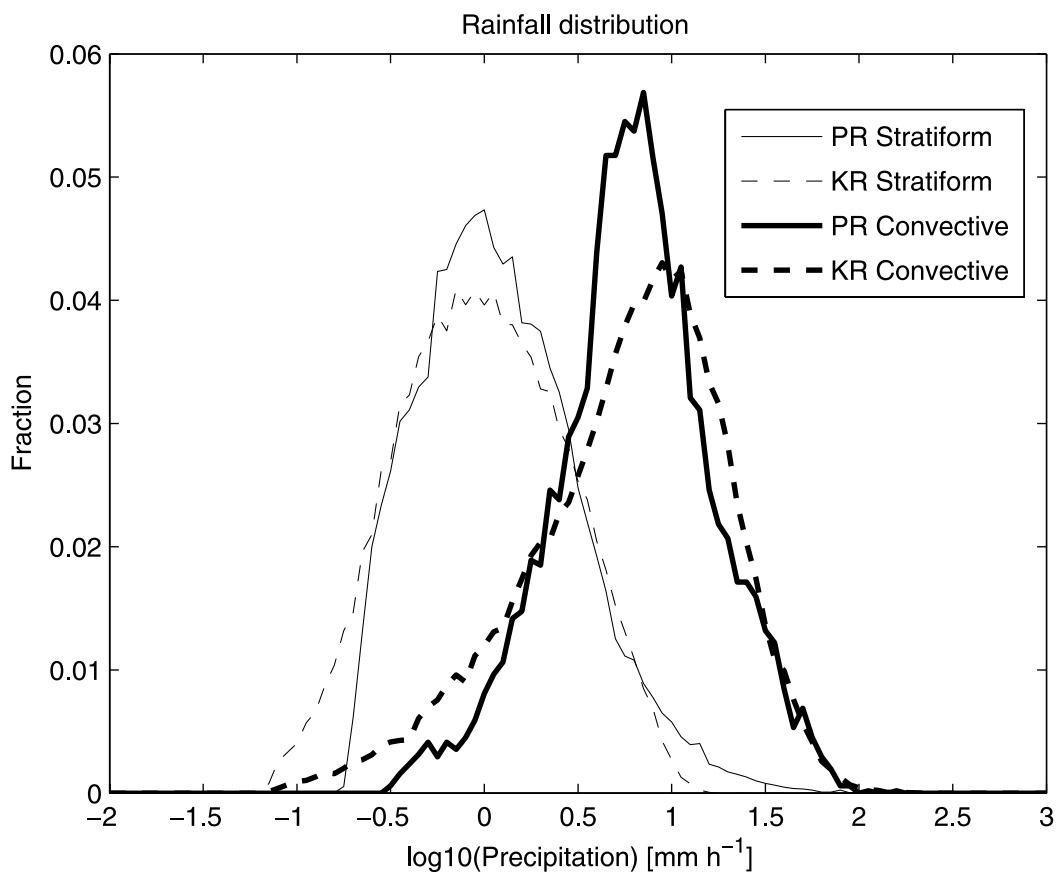

Figure 10. Distribution of the intensity of rainfall for TRMM-PR orbits over Kwajalein. The solid lines are for the TRMM-PR instrument and the dashed lines for the Kwajalein instrument. 
begins abruptly at about $0.2 \mathrm{~mm} \mathrm{~h}^{-1}$ coincident with the lower threshold in reflectivity of the TRMM-PR instrument of about $17 \mathrm{dBZ}$. Also, the mode of the convective precipitation distribution is located at a lower rainfall rate for TRMM probably a consequence of the larger pixel size in the PR ( $4.3 \mathrm{~km}$ compared to $2 \mathrm{~km}$ for KR). For the same reason the KR has a higher frequency of high rainfall rates than TRMM.

[33] The convective stratiform algorithm is applied to the reflectivity data before it has been corrected for attenuation, this might result in a misclassification of some convective echoes into stratiform. Heymsfield et al. [2000] show calculations for a bell-shaped reflectivity distribution intended to mimic a single convective cloud. For instance if we consider a cloud of $1.2 \mathrm{~km}$ in diameter (which is the median diameter of convective updrafts reported over the Kwajalein region between 5 and $9 \mathrm{~km}$ height [Anderson et $a l ., 2005])$ that is centered along the PR beam, the maximum reflectivity is reduced from $50 \mathrm{dBZ}$ to $45 \mathrm{dBZ}$. For the extreme case in which the convective cloud is located in a corner of the PR footprint, reflectivity is further reduced to less than $10 \mathrm{dBZ}$, so in this case not only the cloud would be misclassified but it would be undetected by the PR. Both the misclassification and the nondetection of convective clouds due to beam filtering point in the same direction, toward a negative bias in the value of $\epsilon_{c}$ and a positive bias of $\mathcal{A}_{s}$ toward higher convective fractions. Since we have documented a convective fraction dependence on SST, this very dependence implies a bias with temperature; as a higher proportion of convective cores are present in the sample there will be a larger amount of those cores misclassified or missed by the instrument. Rough estimates using a $20 \%$ of misclassified convective cores and $10 \%$ missing cores can explain a $10 \% / \mathrm{K}$ difference in the value of the relative change of $\mathcal{A}_{s}$. A more precise estimation of this effect could be made observationally by comparing TRMM data before and after the satellite's boost maneuver when pixel size increased from 4.3 to $5.0 \mathrm{~km}$ (for the small set of coincident orbits over Kwajalein, the previous numbers for the percentage of missing and misclassified cores seems reasonable). From cloud physics considerations, and assuming that correlations are primarily controlled by the specific humidity of the boundary layer, one could alternatively argue that the flattening of the correlations toward higher temperatures is due to a saturation effect on the change of the cloud liquid water with temperature rather than an instrumental effect. However, the change over the observed range of temperatures would be too small to explain the flattening. Additionally, an instrumental effect is favored by the fact that in the higher-resolution data of Kwajalein the flattening is less evident.

\subsection{Comparison Between Radar and Infrared Cloud Areas}

[34] The stratiform rainfall area is one of several observables connected to the detrainment from convective clouds. Lindzen et al. [2001] for instance, used the area of clouds between 220 and $260 \mathrm{~K}$ as a proxy for the area of detrainment in deep convective regions. Since the area of precipitation in a convective system is smaller than the area covered by clouds, the use of the stratiform rainfall area minimizes the possibility of an error in which size of the grid over which the statistics are being taken influences the correlations (through the higher rainfall frequency and coverage of the grids at higher SSTs as discussed by $\mathrm{Del}$ Genio and Kovari [2002]). In fact our results do not show a strong dependence on the size of the grids (Table 2). Related to this advantage is the fact that precipitation detrained from the convective region is short-lived with respect to the clouds, and therefore the error which one incurs by truncating the life cycle of the system either in time or in space is minimized (in other words, the convective towers in which detrainment originates are "closer" in time and space to the stratiform rainfall area than to the thin cirrus area). Figure 11 shows the lagged correlation coefficient between the area of stratiform precipitation and the area of the cloud shield over the radar region as measured by the $11 \mu \mathrm{m}$ infrared satellite brightness temperature. In Figure 11 the infrared area excludes regions colder than $220 \mathrm{~K}$ and includes regions colder than a certain temperature $B T$, so we denote this area by $\mathrm{A}(B T-220)$. Lag correlations are maximized along the solid line in Figure 11 with a lag of about $3 \mathrm{~h}$ for $\mathrm{A}(235-220)$ and a lag of about $10 \mathrm{~h}$ for $\mathrm{A}(275-220)$. The relatively large values of the correlation coefficient $(\sim 0.6)$ indicate good correspondence between the rainfall area and the cloud area as measured by the infrared satellite. Moreover, the increase in the time lag in which correlations are maximized for warmer temperatures suggest that even instantaneous measurements as those made by the PR instrument stratiform area capture some information on the time evolution of the detrainment (possibly because the sample includes clouds at various times in their evolution).

\section{Discussion}

[35] We have presented an observational analysis of the dependence of the convective fraction and stratiform area (normalized by total precipitation) on SST. Our motivation for this analysis, as in other previous work, is to explore whether we can obtain constraints on observables that are related to the water budget of deep convective systems in the tropics. The declared or undeclared purpose of such studies (including ours) is not limited to the characterization of the natural variability of convective system in the current climate, but usually there is the expectation that the current variability provided by SST variation in the tropics can serve as a proxy for the changes that can be brought about by climate variability on various scales. There are a number of reasons why a relation between local SST and cloud properties might exist; however, the present study does not depend on these assumptions though it occasionally reflects on them. For instance model simulations and theoretical arguments as well as observations of the present climate indicate that relative humidity remains approximately constant with temperature in the tropical boundary layer [e.g., Held and Soden, 2000]. A simple line of reasoning that follows from this indicates that in a warmer climate, the cloud liquid water will increase in a proportion equal to the relative change in the moist adiabatic lapse rate in the lower part of the cloud (about $2 \% / \mathrm{K}$ at $300 \mathrm{~K}$ ) [e.g., Betts and Harshvardan, 1987], whereas higher up in the cloud, the rate of change will approach the surface Clausius-Clapeyron rate of change (about $6 \% / \mathrm{K}$ at $300 \mathrm{~K}$, if no precipitation is 


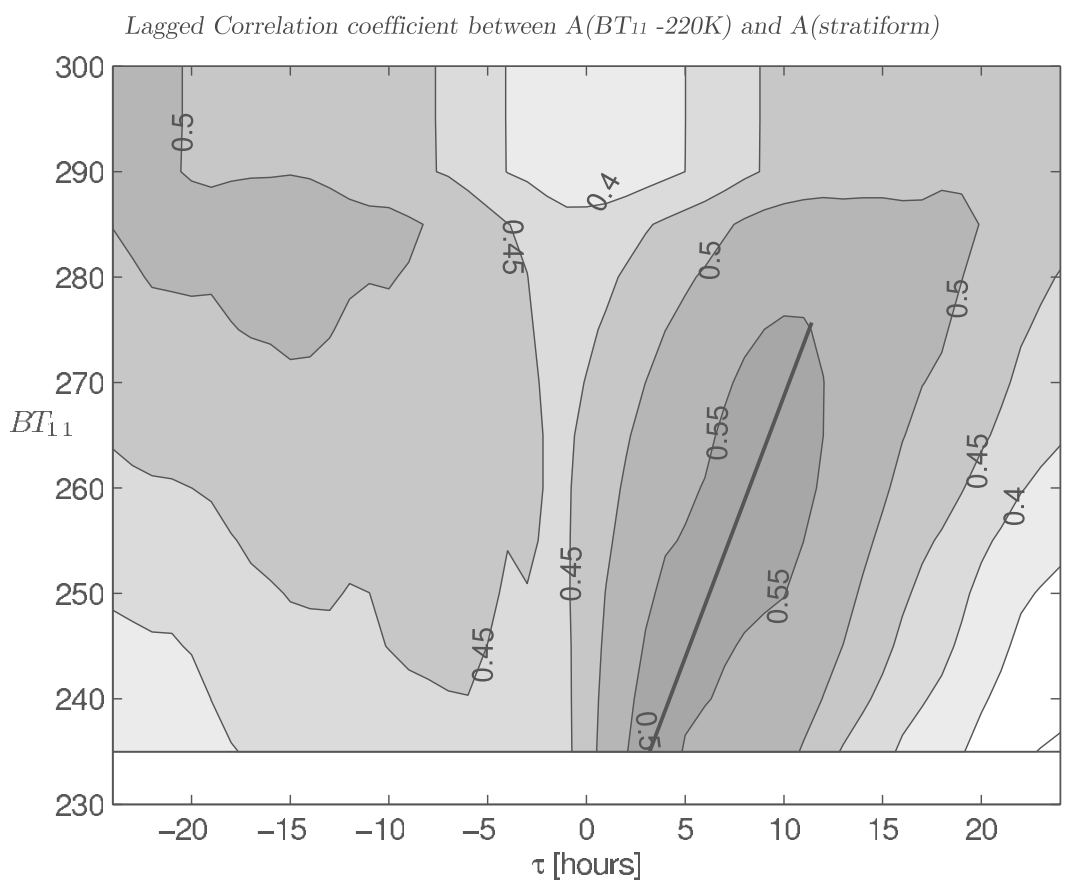

Figure 11. Lagged correlation coefficient between the time series of area of cloud warmer than $220 \mathrm{~K}$ from geostationary brightness temperature data and the area of stratiform precipitation as measured by the Kwajalein radar over a period of 3 months. Solid line indicates the region for which correlations are maximized.

allowed to remove cloud water). Local changes in SST occurring within the present climate can therefore be likened to changes that will occur in a different climate as long as they are uniquely related to changes in specific humidity in the tropical boundary layer. An increase in the liquid water content of the clouds will in turn produce an increase in the time that it takes for precipitation to grow, and simple models as well as sophisticated parameterizations of the microphysics of clouds have incorporated this behavior.

[36] In this paper we focused on the variation with SST of two observables derived from radar data over the tropical oceans: $\epsilon_{c}$, the fraction of convective precipitation, and $\mathcal{A}_{s}$, the area of stratiform precipitation normalized by total precipitation. The normalization is a necessary condition to obtain a meaningful result since to the first order the SST distribution organizes the spatial variation of convection in the tropics. Cloud properties such as the area of detrainment, total rainfall, and cloud radiative effects can be considered extensive with respect to the amount of convection. The normalization simply takes into account the fact that the amount of convection in a region of a given temperature is not indicative of the amount of convection in a climate with the same temperature, since the global amount of convection is determined by global energy balance considerations. It remains an open question whether total precipitation, mass convective flux, or some other measure of convection is the most adequate normalization factor with regard to climate effects.

[37] Our results show an increase in the fraction of convective precipitation with SST together with a decrease of the area of stratiform precipitation per unit of total rainfall. Results for both instruments indicate an increase in the fraction of convective precipitation of about $6-12 \% \mathrm{~K}$ and an decrease in the normalized stratiform area of about $5-28 \% / K$. Furthermore, the observations seem to be independent of the particular geographical area chosen for the analysis, as long as the range of temperatures is sufficiently large.

[38] Although observations are presented here without regard to a specific mechanism, they are in agreement with an increase in precipitation efficiency with temperature required in the functioning of the Iris mechanism [Lindzen et al., 2001]. SST explain a small percentage of the variance for both $\epsilon_{c}$ and $\mathcal{A}_{s}$, but this does not invalidate the existence of a signal. For instance, established correlations such as the correlation between SST and $q$ shown in Figure 2c show substantial scatter, in part due to the reduced range of temperatures in which a signal can be measured. If physical relations between $\epsilon_{c}, \mathcal{A}_{s}$, and SST exist, and especially if these relations are related mechanistically to variations in the boundary layer relative humidity, the scatter between SST and boundary layer specific humidity represents a lower estimate (however, we notice that our observational estimate for this scatter in Figure 2c must be at least in part explained by sampling). Confidence in the physical reality of the signals (i.e., as opposed to noise or instrumental artifacts) is also based upon the generalization of the Kwajalein results to the rest of the tropical oceans using the PR instrument. Additionally, we have tested the sensitivity of the relation to the stratiform-convective separation algorithm (see Appendix A) and the significance of the correlations using a Monte Carlo method (see Appendix B). Furthermore, we emphasize that small values of the regression coefficients as the ones we observe do not imply a 
small effect but rather the presence of noise. The magnitude of the effect is the relevant quantity for estimating possible climate feedbacks.

[39] We notice that the improved linear linear fit (a slight increase in the correlation coefficient and less structure in the residuals of the linear regressions) when specific humidity at the surface is used instead of SST as the independent variable for the Kwajalein data, would seem to point in the direction of boundary layer humidity control of the relation. It has been suggested to us that our observations as well as some other observations that indicate an increase in the efficiency of precipitation with temperature (S. Sherwood, personal communication, 2006) can be explained by the different midtropospheric relative humidity to which convective updrafts are subject. Since regions of relatively warm SST also concentrate most of the precipitation in the tropics, these regions are frequently moister than their colder counterparts. Convection growing in a moister environment has a higher chance of reaching the upper troposphere and suffers less entrainment of dry air that will reduce cloud liquid water content and therefore decrease efficiency of precipitation. On the basis of the Kwajalein data, we observe a weaker dependence of $\epsilon_{c}$ and $\mathcal{A}_{s}$ on the specific humidity above the boundary layer as suggested by the smaller $r$ and slopes when regressions are calculated using $q$ above $800 \mathrm{mb}$. Also, given the fact that our analysis for TRMM includes only deep convective systems, we are already filtering out convective clouds in regions that were too dry to sustain convection. However, the attribution of an specific mechanism (or several) that explain the observations remains an open question.

[40] Several other processes besides SST should have a bearing in the amount of condensate that is detrained from the convective regions and a bias, resulting from the possibility that some of these alternative processes can be controlled by SST as well, cannot be ruled out. Of course such biases would have implications on the question of whether this effect can be extrapolated to a different climate. In tropical climates where temperature gradients in the free troposphere are small, the buoyancy of the convective parcels can be expected to be controlled by the surface density, which in turn is a function of SST. The magnitude of the convective updrafts can have a large effect in the amount of condensate that is detrained from the convective clouds, although a simple relation between the magnitude of the updrafts and buoyancy would seem to indicate the opposite relation as found here (stronger updrafts would produce more detrainment). Several other not so obvious processes that determine the growth and dissipation of precipitation-size particles (e.g., evaporation in the subsaturated environment below the stratiform cloud) could also be controlled by SST. In this respect, it is unclear whether the transport of water vapor to the stratiform region by the midtropospheric ascent can also have an SST dependence, either by changes in the strength of the circulation of the system or by changes in the amount of water vapor that is available to be transported. Some of these questions could begin to be explored by making use of coincident cloud liquid water and precipitation vertical profiles from TRMM and CloudSat instruments.

[41] Recent observational papers have explored the relation between SST and variables related to the efficiency of precipitation in tropical convective systems. Del Genio and Kovari [2002], for instance, studied 6 days of TRMM orbits and found that an index of precipitation efficiency (defined as the ratio between the rain rate and a measure of the specific humidity in the subcloud layer) increases with SST over the regions of deep convective clouds in the tropics. Similarly, Lau and $W u$ [2003] found an increase in the ratio between the cloud liquid water in light warm precipitating clouds, as estimated from passive microwave data from TRMM. Recently, Lin et al. [2006] using ECWMF reanalysis and TRMM data, estimated that the ratio between rainfall rate and the moisture supply to the convective clouds increases by about $2 \% / \mathrm{K}$ in the tropics. These observational studies seem to be consistent with our findings and give support to the possibility of an SST control on the efficiency of precipitation. However, a more definitive claim of consistency would require one to sort out methodological as well as conceptual differences in the definition of precipitation efficiency (this could presumably be done in a cloud resolving model framework). We also notice that some of the previous observational studies emphasize the total change of detrainment area as opposed to the normalized quantity as the relevant measure to evaluate climate feedbacks [e.g., Del Genio et al., 2005]. If model expectations [e.g., Held and Soden, 2006] regarding the relative change of rainfall with temperature are realized, we could expect that any decrease in the normalized area of detrainment at a rate larger than $2 \% / \mathrm{K}$ would imply a global decrease in the area detrainment, and to the extent that tropical cirrus clouds have a net warming effect on climate, this decrease would imply a negative cloud feedback.

\section{Appendix A: Sensitivity to Stratiform-Convective Horizontal Separation Algorithm}

[42] For completeness, we include a detailed account of the stratiform-convective separation algorithm based on the work of Steiner et al. [1995] and Yuter and Houze [1997]. The rules applied in order to classify each pixel are highly dependent on the horizontal resolution of the radar and they need to be calibrated by selecting arbitrary thresholds. The calibration is done by inspecting the vertical radar reflectivity in which coherent high-reflectivity levels and bright bands can be identified and the thresholds be set accordingly. The method only uses the horizontal information for the classification of the echoes. The the lowest-level reflectivity measured by the radar (base reflectivity) is examined and the following rules are applied to identify convective regions:

[43] 1. Pixels in which the radar intensity exceeds a threshold $Z_{t h}$ are immediately classified as convective. This default threshold value is initially set to $40 \mathrm{dBZ}$.

[44] 2. Pixels for which the background reflectivity $Z_{b g}$ (measured as the arithmetic average reflectivity of an area of $11 \mathrm{~km}$ radius surrounding each precipitating pixel) exceeds a background reflectivity threshold given by the formula,

$$
\Delta Z_{t h}=a \cos \left(\frac{\tau}{2 b} Z_{b g}\right)
$$

are also classified as convective. 
Table A1. Sensitivity of the Correlations Between $\epsilon_{c}$ and $\mathcal{A}_{s}$ With SST to the Different Parameters of the Stratiform-Convective Separation Algorithm Using the University of Washington Kwajalein Base Data Set ${ }^{\mathrm{a}}$

\begin{tabular}{|c|c|c|c|c|c|c|c|c|}
\hline \multirow[b]{2}{*}{ Result } & \multirow{2}{*}{$\begin{array}{c}a \\
(\mathrm{dBZ})\end{array}$} & \multirow{2}{*}{$\begin{array}{c}b \\
\text { (dBZ) }\end{array}$} & \multirow{2}{*}{$\begin{array}{c}Z_{\text {th }} \\
(\mathrm{dBZ})\end{array}$} & \multirow{2}{*}{$\begin{array}{l}\text { Method } \\
(\mathrm{M} / \mathrm{N})^{\mathrm{b}}\end{array}$} & \multicolumn{2}{|c|}{$\epsilon_{c}$} & \multicolumn{2}{|c|}{$\mathcal{A}_{s}$} \\
\hline & & & & & $\% / \mathrm{K}$ & $r$ & $\% / \mathrm{K}$ & $r$ \\
\hline 1a & 10 & 55 & 40 & M & 8.0 & 0.38 & -27 & 0.40 \\
\hline $1 b$ & 10 & 45 & 40 & & 6.5 & 0.38 & -25 & -0.49 \\
\hline $1 \mathrm{c}$ & 10 & 65 & 40 & M & 9.3 & 0.39 & -25 & -0.51 \\
\hline $2 a$ & 5 & 55 & 40 & M & 3.1 & 0.35 & -25 & -0.50 \\
\hline $2 b$ & 15 & 55 & 40 & M & 23 & 0.49 & -26 & -0.52 \\
\hline $3 a$ & 10 & 55 & 45 & M & 8.2 & 0.37 & -25 & 0.51 \\
\hline $3 b$ & 10 & 55 & 35 & M & 9.8 & 0.47 & -27 & -0.51 \\
\hline 4 & 10 & 55 & 40 & $\mathrm{~N}$ & 7.25 & 0.29 & -24 & -0.52 \\
\hline
\end{tabular}

${ }^{\mathrm{a}}$ The calculations were repeated in each case for the complete 19992003 period.

${ }^{b} \mathrm{M}$ refers to medium method as in the work of Steiner et al. [1995]. N refers to no method for the size of the convective region.

[45] 3. Finally, after the two previous rules have been applied the algorithm selects a region around each convective pixel in which pixels will be classified as convective. The radius of this region is designed to be a function of the mean background reflectivity $\overline{Z_{b g}}$, under the premise that a brighter background region will indicate a more active and larger convective region.

[46] The technique has many degrees of freedom and therefore requires calibration against some independent data set, usually the vertical profile of reflectivity from which a bright band can be identified [Steiner et al., 1995]. Here we explore the sensitivity of the Kwajalein results to the design parameters of the algorithm.

[47] We have performed a sensitivity study using the base reflectivity data for the complete period of 1999-2003. Once the algorithm is applied and a classification between stratiform and convective echoes is achieved, the surface rainfall is recalculated applying the calibration and corrections described by Houze et al. [2004]. Table A1 summarizes the results of the sensitivity tests using the different parameters the stratiform convective for the particular period. The rows labeled from 1 a to 4 refer to the results of the sensitivity to the parameters. The row 1 a attempts to simulate the classification found in the original data set with minor differences.

[48] Correlations between $\mathcal{A}_{s}$ and SST are relatively insensitive to the parameters of the classification, whereas a more significant variation (from $3 \%$ to $23 \%$ ) is observed in the change of $\epsilon_{c}$ with respect to the classifications parameters. Both correlations are relatively insensitive to changes in the reflectivity threshold $Z_{t h}$ (compare case 1a to cases $3 \mathrm{a}$ and $3 \mathrm{~b}$ ), presumably because pixels that are left out of the convective classification by a stronger threshold (as in case 3a) will still be considered convective by one of the other two criteria. On the other hand, a larger sensitivity is obtained, especially for the slope of the regression with $\epsilon_{c}$, by changing the parameter $a$ (cases $2 \mathrm{a}$ and $2 \mathrm{~b}$ ) which is related to the area surrounding a particularly intense reflectivity region that is considered convective. We conclude that to the extent that the algorithm parameters are modified within reasonable values from those used for calibrating the algorithm, the correlations are not significantly modified. It is also clear that critical for an accurate quantification of the variation of $\epsilon_{c}$ with SST is accuracy on the detection of the size of the convective region.

\section{Appendix B: Statistical Significance of the Kwajalein Results}

[49] We have tested the statistical significance of these results by using some of the observed characteristics of the time series of SST and $\epsilon_{c}$ and constructing a simple statistical model to apply a Monte Carlo method. The
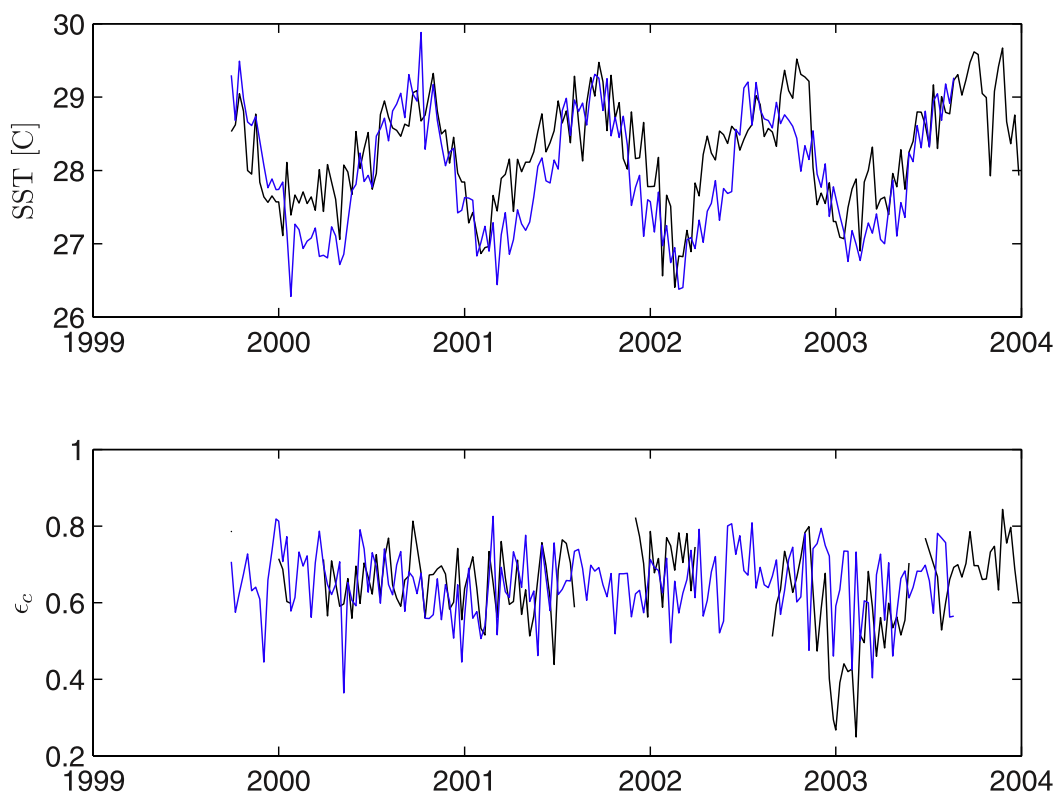

Figure B1. (top) The actual SST time series (black) and one of the Montecarlo simulations according to equation (B1). (bottom) The actual $\epsilon_{c}$ corresponding to the plotted months, and the simulated $\epsilon_{c}$ from equation (B2) (blue). 


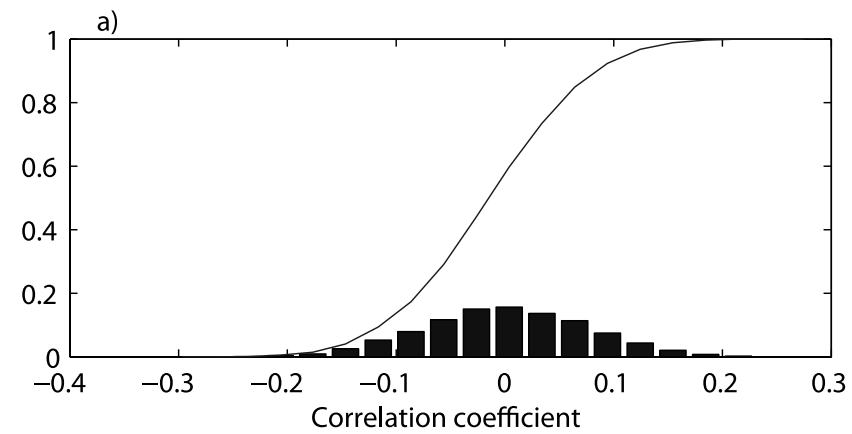

b)

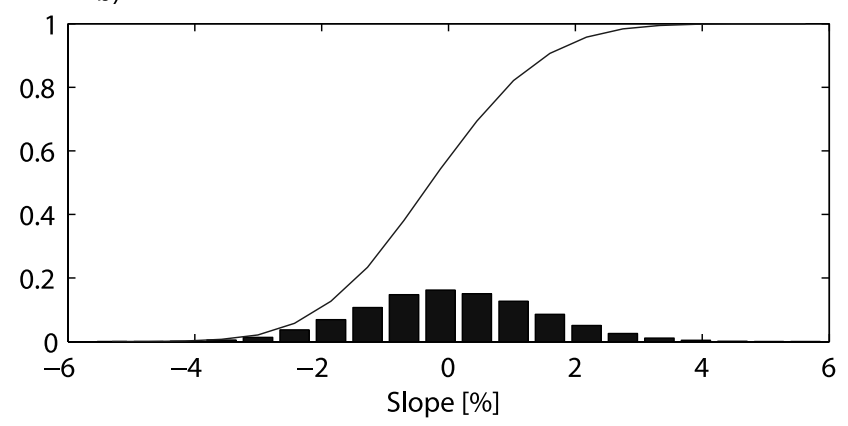

Figure B2. Empirical distribution and cumulative frequency of the Monte Carlo simulations of the processes for a constant variance.

appropriate statistical model satisfies the null hypothesis $H_{0}$ : $\epsilon_{c}$ and SST are independent. Therefore the approach to test the significance of the results will be to simulate through this statistical model calibrated through the observations, several pairs of values $\left(\epsilon_{c}^{t, n}, \mathrm{SST}^{t, n}\right)$, where $t=1 . . t_{f}$ are the times over which the series of measurements are taken (in this case each $t$ represents an 8-day period) and $n$ is an index that indicates a single realization.

[50] First, we define an idealized time series for the SST based on the observed time series for SST in Kwajalein as,

$$
S S T^{t, n}=\overline{S S T}+\cos \left(2 \pi t / t_{y}\right)+\mathcal{N}^{t, n}\left(0, \sigma_{S S T}\right)
$$

where $\overline{S S T} \sim 28 \mathrm{C}$ and $\sigma_{S S T} \sim 0.3 \mathrm{C}$ are the observed mean and standard deviation of the high pass filtered time series of SST. The time $t_{y}$ is the number of periods in a year so the cosine is meant to represent an annual cycle in SST with an amplitude of $1 \mathrm{C} . \mathcal{N}^{t, n}$ is a realization from the normal distribution meant to represent the high-frequency variability of SST.

[51] From these realizations of $S S T$ we can propose a model for the behavior of $\epsilon_{c}$ consistent with the null hypothesis. That is,

$$
\epsilon_{c}^{t, n}=\overline{\epsilon_{c}}+\mathcal{N}^{t, n}\left(0, \sigma_{\epsilon_{c}}\right)
$$

We have pointed out that the variance of $\epsilon_{c}$ seems to decrease with SST (due in part to a decrease in the component of the variance related to sampling) so that the statistical significance determined from Monte Carlo simulations can be affected by whether we consider $\sigma \epsilon_{c}$ as a constant or as a function of SST. So strictly speaking two slightly different null hypotheses will be discussed: one in which there is strict independence and the other one in which the dependence is constrained to appear only in the SST dependence of the variance. Figure B1 shows the original time series for $S S T$ and $\epsilon_{c}$ and a single realization of the model using the sampling dependence of the variance.

[52] For the cases in which there is an SST-dependent variance a simple linear dependence is written,

$$
\sigma_{\epsilon_{c}}(S S T)=\left(S S T_{0}-S S T\right) \beta+\sigma_{\epsilon_{c}}\left(S S T_{0}\right),
$$

with empirically derived values for $\beta=0.025$ and $\sigma\left(S S T_{0}=\right.$ $26 C)=0.14$.

[53] Results for the Monte Carlo simulations of the statistical process described in equation (B2) using a constant value for $\sigma \epsilon_{c}$ equal to the empirically observed value of 0.1 and a value of $\overline{\epsilon_{c}}=0.667$ are shown in Figure B2 and B3. The results are for 10,000 realizations. The empirical distribution for both the slopes and the correlation coefficients are centered around zero. Comparing the values for the slope and the correlation coefficient obtained for the 8day period averages, the null hypothesis is rejected under this assumption at a relatively high significance level (slopes higher than $4.4 \%$ and correlation coefficients higher than 0.22 are significant at the $0.1 \%$ level).

[54] However, as previously mentioned, a test in which the variance of the statistic $\epsilon_{c}$ is regarded as constant might be liberal in rejecting the null hypothesis. In fact, introducing an SST dependence in the value of $\sigma_{\epsilon_{c}}$ according to equations (B2) and (B3), we observe that the distribution of slopes and correlation coefficients becomes skewed toward positive values. Therefore, a relatively larger value in the slopes and correlation coefficient is required (slopes higher than $5.2 \%$ and correlation coefficients higher than 0.28 are significant at the $0.1 \%$ level). When comparing the value of the statistics related to these significance numbers to the values of the slope and correlation coefficient obtained in
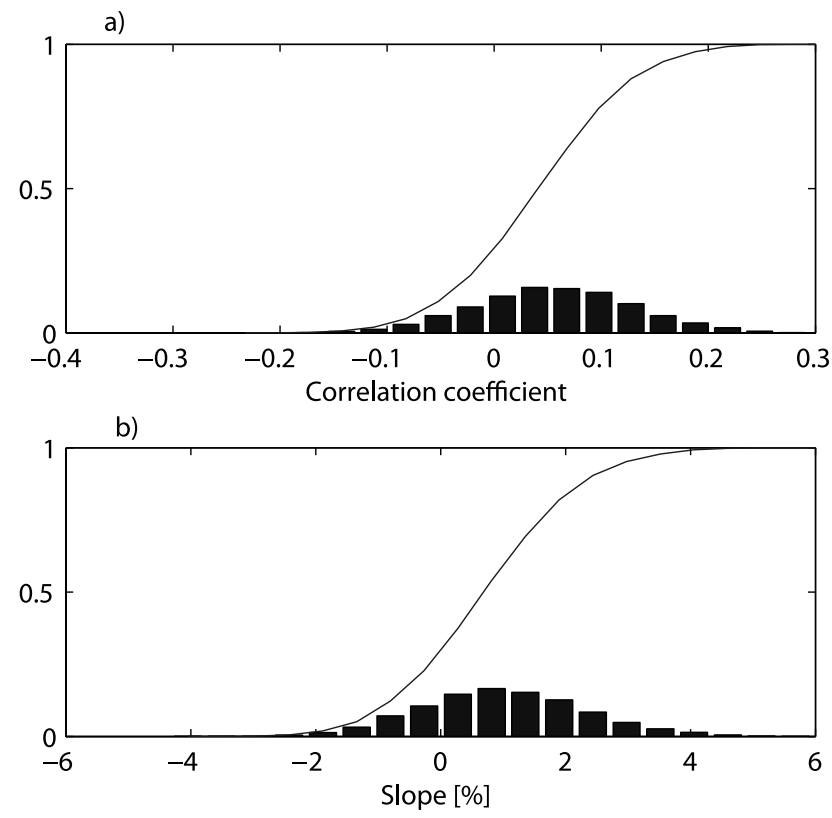

Figure B3. Same as Figure B2 but for an SST-dependent variance according to (B3). 
the corresponding observations (i.e., $r=0.42$ and slope $11.8 \%$ ) we conclude that even in this case the null hypothesis is rejected with a high confidence level. Similar analyses performed for $\mathcal{A}_{s}$ show that the decrease with SST is also statistically significant.

[55] Acknowledgments. The data used in this study were acquired as part of the Tropical Rainfall Measuring Mission (TRMM). The algorithms were developed by the TRMM Science Team. The data were processed by the TRMM Science Data and Information System (TSDIS) and the TRMM Office; they are archived and distributed by the Goddard Distributed Active Archive Center. TRMM is an international project jointly sponsored by the Japan National Space Development Agency (NASDA) and the U.S. National Aeronautics and Space Administration (NASA) Office of Earth Sciences. This work was supported by DOE grant DE-FG02-01ER63257. We thank two anonymous reviewers for critically reading the manuscript and making several useful remarks.

\section{References}

Anderson, N., C. Grainger, and J. Stith (2005), Characteristics of strong updrafts in precipitation systems over the central tropical Pacific Ocean and in the Amazon, J. Appl. Meteorol., 44(5), 731-738.

Awaka, J., T. Iguchi, H. Kumagai, and K. Okamoto (1997), Rain type classification algorithm for TRMM precipitation radar, IEEE Trans. Geosci. Remote Sens., 4, 1633-1635.

Bell, T., and P. Kundu (2000), Dependence of satellite sampling error on monthly averaged rain rates: Comparison of simple models and recent studies, J. Clim., 13(2), 449-462.

Berg, W., C. Kummerow, and C. Morales (2002), Differences between east and west Pacific rainfall systems, J. Clim., 15(24), 3659-3672.

Betts, A. and Harshvardan (1987), Thermodynamic constraint on the cloud liquid water feedback in climate models, J. Geophys. Res., 92(D7), $8483-8485$.

Choi, Y.-S., and C.-H. Ho (2006), Radiative effect of Cirrus with different optical properties over the tropics in MODIS and CERES observations, Geophys. Res. Lett., 33, L21811, doi:10.1029/2006GL027403.

Churchill, D. D., and R. A. Houze (1984), Development and structure of winter monsoon cloud clusters on 10 December 1978, J. Atmos. Sci., 41(6), 933-960.

Clement, A., and B. Soden (2005), The sensitivity of the tropical-mean radiation budget, J. Clim., 18(16), 3189-3203.

Cotton, W., G. Alexander, R. Hertenstein, R. Walko, R. McAnelly, and M. Nicholls (1995), Cloud venting-A review and some new global annual estimates, Earth Sci. Rev., 39(3-4), 169-206.

Del Genio, A., and W. Kovari (2002), Climatic properties of tropical precipitating convection under varying environmental conditions, J. Clim., 15(18), 2597-2615.

Del Genio, A. D., W. Kovari, M.-S. Yao, and J. Jonas (2005), Cumulus microphysics and climate sensitivity, J. Clim., 18(13), 2376-2387.

Doviak, R. J., and D. S. Zrnic (1993), Doppler Radar and Weather Observations, 2nd ed., Academic, San Diego, Calif.

Emanuel, K. A., and R. T. Pierrehumbert (1996), Microphysical and dynamical control of tropospheric water vapor, in Clouds, Chemistry and Climate, vol. 135, edited by V. Ramanathan, pp. 17-28, Springer, Berlin.

Ferrier, B., J. Simpson, and W. Tao (1996), Factors responsible for precipitation efficiencies in midlatitude and tropical squall simulations, Mon. Weather Rev., 124(10), 2100-2125.

Gamache, J. F., and R. A. Houze (1983), Water budget of a mesoscale convective system in the tropics, J. Atmos. Sci., 40(7), 1835-1850.

Held, I., and B. Soden (2000), Water vapor feedback and global warming, Annu. Rev. Energy Environ., 25, 441-475.

Held, I., and B. Soden (2006), Robust responses of the hydrological cycle to global warming, J. Clim., 19(21), 5686-5699.

Heymsfield, G., B. Geerts, and L. Tian (2000), TRMM precipitation radar reflectivity profiles as compared with high-resolution airborne and groundbased radar measurements, J. Appl. Meteorol., 39(12), 2080-2102.

Houze, R. A. (1993), Cloud Dynamics, vol. 53, Academic, San Diego, Calif.
Houze, R. A. (1997), Stratiform precipitation in regions of convection: A meteorological paradox?, Bull. Am. Meteorol. Soc., 78(10), 2179-2196.

Houze, R. A., Jr. (2004), Mesoscale convective systems, Rev. Geophys., 42 , RG4003, doi:10.1029/2004RG000150.

Houze, R. A., S. Brodzik, C. Schumacher, S. E. Yuter, and C. R. Williams (2004), Uncertainties in oceanic radar rain maps at Kwajalein and implications for satellite validation, J. Appl. Meteorol, 43(8), 1114-1132.

Iguchi, T., T. Kozu, R. Meneghini, and J. Awaka (2000), Rain-profiling algorithm for the TRMM precipitation radar, J. Appl. Meteorol., 39(12), $2038-2052$.

Johnson, R., T. Rickenbach, S. Rutledge, P. Ciesielski, and W. Schubert (1999), Trimodal characteristics of tropical convection, J. Clim., 12(8), $2397-2418$

Kummerow, C., W. Barnes, T. Kozu, J. Shiue, and J. Simpson (1998), The tropical rainfall measuring mission TRMM sensor package, J. Atmos. Oceanic Technol., 15, 809-817.

Lau, K., and H. Wu (2003), Warm rain processes over tropical oceans and climate implications, Geophys. Res. Lett., 30(24), 2290, doi:10.1029/ 2003GL018567.

Lau, K., H. Wu, Y. Sud, and G. Walker (2005), Effects of cloud microphysics on tropical atmospheric hydrologic processes and intraseasonal variability, J. Clim., 18(22), 4731-4751.

Lin, B., B. A. Wielicki, P. Minnis, L. Chambers, K. M. Xu, Y. X. Hu, and A. Fan (2006), The effect of environmental conditions on tropical deep convective systems observed from the TRMM satellite, J. Clim., 19(22), $5745-5761$

Lindzen, R. S., M.-D. Chou, and A. Y. Hou (2001), Does the Earth have an adaptive infrared iris?, Bull. Am. Meteorol. Soc., 82(3), 417-432.

Rapp, A., C. Kummerow, W. Berg, and B. Griffith (2005), An evaluation of the proposed mechanism of the adaptive infrared iris hypothesis using TRMM VIRS and PR measurements, J. Clim., 18(20), 4185-4194.

Renno, N., K. Emanuel, and P. Stone (1994), Radiative-convective model with an explicit hydrologic cycle: 1 . Formulation and sensitivity to model parameters, J. Geophys. Res., 99, 14,429-14,442, doi:10.1029/ 94JD00020.

Rutledge, S. A., and R. A. Houze (1987), A diagnostic modeling study of the trailing stratiform region of a midlatitude squall line, J. Atmos. Sci., 44(18), 2640-2656.

Schumacher, C., and R. A. Houze (2000), Comparison of radar data from the trmm satellite and kwajalein oceanic validation site, J. Appl. Meteorol., $39(12), 2151-2164$

Schumacher, C., and R. Houze (2003), Stratiform rain in the tropics as seen by the TRMM precipitation radar, J. Clim., 16(11), 1739-1756.

Schumacher, C., and R. Houze (2006), Stratiform precipitation production over sub-Saharan Africa and the tropical East Atlantic as observed by TRMM, Q. J. R. Meteorol. Soc., 132(620), 2235-2255.

Spencer, R., W. Braswell, J. Christy, and J. Hnilo (2007), Cloud and radiation budget changes associated with tropical intraseasonal oscillations, Geophys. Res. Lett., 34, L11104, doi:10.1029/2007GL029844.

Steiner, M., R. A. Houze, and S. E. Yuter (1995), Climatological characterization of three-dimensional storm structure from operational radar and rain gauge data, J. Appl. Meteorol., 34(9), 1978-2007.

Su, H., J. H. Jiang, Y. Gu, J. D. Neelin, J. W. Waters, B. H. Kahn, N. J. Livesey, and M. L. Santee (2008), Variations of tropical upper tropospheric clouds with sea surface temperature and implications for radiative effects, J. Geophys. Res., 113, D10211, doi:10.1029/2007JD009624.

Sun, D., and R. S. Lindzen (1993), Distribution of tropical tropospheric water vapor, J. Atmos. Sci., 50(12), 1643-1660.

TRMM Precipitation Radar Team (2005), Tropical Rainfall Measuring Mission (TRMM) precipitation radar algorithm: Instruction manual for version 6, Jpn. Aerosp. Explor. Agency Natl. Aeronaut. and Space Admin., Tokyo.

Yuter, S. E., and R. A. Houze (1997), Measurements of raindrop size distributions over the Pacific warm pool and implications for Z-R relations, J. Appl. Meteorol., 36(7), 847-867.

R. S. Lindzen and R. Rondanelli, Program in Atmosphere, Oceans, and Climate, Massachusetts Institute of Technology, 54-1717, 77 Massachusetts Avenue, Cambridge, MA 02139, USA. (rrondane@mit.edu) 